CIRJE-F- 1073

\title{
Excess Capacity and Effectiveness of Policy Interventions: Evidence from the Cement Industry
}

\author{
Tetsuji Okazaki \\ The University of Tokyo \\ Ken Onishi \\ Federal Reserve Board \\ NaokiWakamori \\ The University of Tokyo
}

December 2017; Revised in December 2018 and May 2021

CIRJE Discussion Papers can be downloaded without charge from:

http://www.cirje.e.u-tokyo.ac.jp/research/03research02dp.html

Discussion Papers are a series of manuscripts in their draft form. They are not intended for circulation or distribution except as indicated by the author. For that reason Discussion Papers may not be reproduced or distributed without the written consent of the author. 


\title{
Excess Capacity and Effectiveness of Policy Interventions: Evidence from the Cement Industry*
}

\author{
Tetsuji Okazaki ${ }^{\dagger}$
}

\author{
Ken Onishi ${ }^{\ddagger}$
}

\author{
Naoki Wakamori ${ }^{\S}$
}

May 28, 2021

\begin{abstract}
Strategic interaction among firms may hinder the reduction of excess capacity in a declining industry. Policy interventions that attempt to reduce excess capacity may increase efficiency by accelerating the capital adjustment but may decrease efficiency by increasing the market power of firms and/or by distorting firms' divestment decisions. We study capacity coordination policies-forcing firms to reduce their capacity simultaneously - applied to the Japanese cement industry. Estimation results suggest that these interventions did not increase market power because reduction in capacity resulted in higher utilization of the remaining plants, and did not distort firms' scrappage decisions.
\end{abstract}

JEL Classification: D24, L13, L52, L61.

Keywords: Excess Capacity, Capacity Coordination, Cartels, Cement.

\footnotetext{
${ }^{*}$ We are grateful to Masato Nishiwaki for his helpful discussion and constructive comments. We also wish to thank Naoshi Doi, Serafin J. Grundl, Mitsuru Igami, You Suk Kim, Masayuki Morikawa, Martin Peitz, Philipp Schmidt-Dengler, Oleksandr Shcherbakov, Yuya Takahashi, Frank Verboven, Makoto Yano, and the participants at many conferences and seminars. We are grateful to the Japan Cement Association for providing some materials and giving advice on cement technology. Okazaki and Wakamori gratefully acknowledge financial support from the JSPS KAKENHI Grant Numbers JP26285053 and JP19K13675. The analysis and conclusions set forth are those of the authors and do not indicate concurrence by other members of the staff, by the Board of Governors of the Federal Reserve System, or by the Federal Reserve Banks. Any remaining errors are our own.

${ }^{\dagger}$ The University of Tokyo, okazki@e.u-toyko.ac.jp.

${ }^{\ddagger}$ Federal Reserve Board, ken.t. onishi@frb.gov.

${ }^{\S}$ (Corresponding Author) The University of Tokyo, nwakamo@e .u-tokyo .ac.jp.
} 


\section{Introduction}

Excess production capacity, also known as overcapacity, has been a major concern in many countries, in particular when an industry faces declining demand-e.g., the US steel industry in the 1970s, the hard disk drive industry in Asia in the 2010s, the current shipbuilding industry in China and Korea, and the current US hydraulic fracturing industry. The excess capacity literature dates back to at least Bain (1962), who defines excess capacity as a "persistent tendency toward redundant capacity at times of maximum or peak demand." Excess capacity is one source of social inefficiency; it might cause capital misallocation, create unnecessary running costs or limit land use. Although policymakers have been particularly concerned about this excess capacity issue, as discussed in several high-level meetings and policy roundtables at the OECD, economists have yet to provide a rigorous empirical analysis, believing that this problem may be resolved through a market mechanism and natural selection, as theoretically shown by Ghemawat and Nalebuff (1990). However, it is also well known that firms' strategic interaction may delay the exit and divestment process when oligopolistic firms are waging a "war of attrition" (Smith, 1974). Such a strategic delay may create social inefficiency, as empirically confirmed by Takahashi (2015). Thus, explicit cooperation among firms may improve efficiency, though it may be prohibited from an anti-trust point of view.

Capacity coordination, allowing firms to coordinate their capacity, is a common policy intervention in a distressed industry, to accelerate the process of capacity adjustment. Even though it is, in principle, prohibited due to its collusive nature, there are some cases where exemptions were granted. Competition law in Europe may allow firms in a recession industry to form crisis cartels-e.g., the European synthetic fiber industry in the 1980s and the Dutch brick industry in the 1990s. Even recently, in the United States, two airline companies in Hawaii were allowed to coordinate their capacity in response to declining demand after the September 11, 2001, terrorist attacks. Though we observe such occasional capacity coordination policies in many countries, to the best of our knowledge, the literature has not comprehensively examined them yet. Therefore, in order to consider policy design, this paper attempts to empirically evaluate capacity coordination policies from the viewpoints of both consumers and producers.

To this end, this paper focuses on a series of capacity coordination policies applied to the Japanese cement industry in the 1980s and 1990s, which provides an ideal environment with detailed data for precisely evaluating how capacity coordination policies 
would enhance and harm welfare. We believe that this case is ideal because of (i) its historical background and market structure, (ii) the characteristics of cement-a homogeneous product and simple production process-and (iii) availability of excellent data. First, even though the industry faced declining demand in the 1970s triggered by two oil crises, the oligopolistic firms did not adjust their capacity to the change in demand, which led to low capacity utilization. Observing this, the Ministry of International Trade and Industry (hereinafter MITI) initiated a series of policies called "capacity coordination" that forced the cement firms to divest their production capacity simultaneously, based on the allotment authorized by MITI. Second, thanks to the homogeneity of the product and simplicity of the production process, we can estimate the demand function and production function accurately. These recovered primitives enable us to obtain firms' markups and plant productivity, which we relate consumer welfare and firms' behavior. Furthermore, very detailed plant-level data are available for this industry; for each plant, we observe not only the production amount and capacity, which enables us to calculate the utilization rate of a plant, but also how many and which type of kilns (technology) each plant owned.

Our empirical analysis begins with examining the changes in firms' market power, which is closely related to consumer welfare. In particular, we specifically ask whether these policy interventions increased prices and/or markups, due to the collusive nature of capacity coordination. The first capacity coordination policy targeted a reduction of 30 million out of the 129 million tons of existing capacity and, out of that 30 million tons, 25 million tons was from nonoperating capacity and 5 million tons was from operating capacity-whereas the second capacity coordination policy targeted a further reduction of 10.7 million of the existing 98 million tons, all of which was from operating capacity. Thus, we naturally expect that firms would be able to set higher markups after the policy implementations, because these capacity coordination policies forced the firms to divest operating capacity and thus the supply could no longer meet the demand. To answer the question, we first recover the demand function and obtain the plant-level marginal costs based on the first-order conditions for the firms. We then use regression analysis and find that neither capacity coordination policy increased the markups charged by the cement firms. These results are counterintuitive, but further investigation reveals that the cement firms concentrated their production within the remaining plants and the utilization rates for those plants increased to almost $100 \%$. In other words, although the capacity coordination policies forced the firms to shut down some operating plants, they could 
meet demand by fully utilizing their remaining capacity. Therefore, the policies allowed the firms to save unnecessary running costs by divesting the plants with low utilization rates, which enhanced social welfare given that consumer welfare was not harmed.

The data clearly demonstrate that a series of policies successfully accelerated the capital adjustment process, and this observation raises the next set of questions: whether this policy intervention distorted the scrappage decisions of the firms and whether the divested plants were also inefficient from a social point of view. To do so, we first recover plant-level productivity via production function estimation and relate productivity to their divestment decisions. Our estimation results show that the firms were likely to divest inefficient plants before the policy introduction and their scrappage decision rules were unchanged during the policy implementation period. The results are robust, regardless of our measurements of productivity—labor productivity, utilization rates, or TFP from production function estimation—and regardless of measurements of divestmentdifference in capacities or difference in the number of kilns. Furthermore, our estimation results also support that these divested plants were inefficient not only from the viewpoint of the firms but also from the viewpoint of social welfare.

From our empirical analysis, we conclude that, if allotments and total reduction capacity are well crafted, capacity coordination policy potentially accelerates the divestment process, which increases producer surplus, without lowering consumer welfare. In particular, capacity coordination could effectively reduce excess capacity without distorting firms' scrappage decisions. Moreover, those divested plants were unproductive from the viewpoint of social welfare.

This paper contributes to the literature on industrial policies, declining industries and capacity coordination. First of all, we would like to emphasize that our paper contributes to a literature on industrial policies, which has attracted attention from the viewpoints of both academics and policy makers. Industrial policies have been re-evaluated in the literature recently (see Aghion, Cai, Dewatripont, Du, Harrison and Legros (2015), Kalouptsidi, Barwick and Zahur (2020), and Aiginger and Rodrik (2020)) reflecting the rise in the Chinese economy. Even though the existing studies mostly focus on policies employed by developing countries to foster specific industries, we believe that industrial policies applied to declining industries are equally important and may be more effective, because, for declining industries, enough data on demand and cost structure and industrial knowledge have accumulated and available to policy makers that we can prevent further inefficiencies. We therefore contribute to the literature by studying another as- 
pect of industrial policies that is understudied.

Second, even though the study of declining industries is becoming increasingly important, there are only a handful of theoretical and empirical studies in this area. Das (1992) considers US cement firms' divestment decisions when facing declining demand, both theoretically and empirically. Ghemawat and Nalebuff (1985, 1990), Fudenberg and Tirole (1986), and Whinston (1988) consider an oligopolistic market and examine firms' decisions to divest and/or exit when the industry faces declining demand. On the empirical side, Lieberman (1990), Deily (1991), and Nishiwaki and Kwon (2013) study firms' exit or plants' closure behavior relating to the firms' observable characteristics and unobserved productivity. More recently, Nishiwaki (2016b) and Takahashi (2015), using a structural approach, study firms' exit and divestment decisions, respectively, in declining industries. Nishiwaki (2016b) examines the effect of mergers on divestment behavior in the Japanese cement industry and finds that strategic interaction, through business stealing in particular, distorts incentives for divestment. Takahashi (2015) estimates an exit game played by US movie theaters, which builds on a theoretical framework developed by Fudenberg and Tirole (1986), and finds that strategic interaction among the theaters delays the exit date substantially. Both results suggest that policy intervention may help restore efficiency by eliminating strategic interaction among firms, which motivates us to thoroughly examine how capacity coordination policies work in this paper.

Excess capacity in declining industries creates social inefficiency, and one of the policy instruments discussed among policymakers that can address this inefficiency is capacity coordination. Kamita (2010) investigates a recent case from the US airline industry: the Aloha-Hawaiian immunity agreement. In response to declining demand after September 11, 2001, the US Department of Transportation allowed Aloha Airlines and Hawaiian Airlines to coordinate capacity for a limited time. ${ }^{1}$ She finds that the two firms maintained high prices not only during the immunity period, but also during the subsequent 2.5 years, until a new competitor entered the market. Although empirical analysis on capacity coordination is scarce, Hampton and Sherstyuk (2012) conduct an experimental study on this topic. They show that capacity coordination by an enforceable institution-the government initiative in our context or agreements with enforceable punishment in the Aloha-Hawaiian case-accelerates the capital adjustment process. While their main focus is the effects of capacity coordination on prices and the speed of the capital adjustment process, we also examine its implications for the effectiveness

\footnotetext{
${ }^{1}$ See Blair, Mak and Bonham (2007) for more detailed information.
} 
and efficiency of capacity coordination policy.

This paper is organized as follows. Section 2 describes the industry and provides the historical background of the Japanese cement industry as well as the data used in our empirical analysis. Our empirical models and estimation results are presented in Section 3. Given our findings, we discuss the policy implications and caveats in Section 4. Section 5 concludes.

\section{Industry and Historical Background}

\subsection{Cement and Its Production Technology}

Cement is one of the most important ingredients for construction work, as concrete and mortar are made from cement. To produce cement, crushed limestone, clay and other minerals are mixed and put into a kiln to be heated. This process yields clinker, which is an intermediate cement product. Note that once cement kilns start the heating process, they are kept heated until the next regular maintenance, which occurs once or twice a year, as rebooting takes a long time and involves energy loss. Even though kilns run 24 hours a day, firms can control the output and utilization rate by adjusting the input. Thus, low utilization rates potentially create inefficiency from unnecessary running costs. The final procedure of mixing grinded clinker with gypsum produces cement. The simplicity of this process and homogeneity of the product allow us to analyze and evaluate the capacity coordination policy precisely. In our analysis, we mainly use clinker as our measure of output, because some plants specialize in the production of cement from clinker and do not own any kilns.

Cement kilns are the heart of the production process, and it is important for us to understand some technological aspects of cement kilns in Japan. Even though there are several types of kilns, we can roughly categorize them into two types: dry process kilns and wet process kilns. ${ }^{2}$ Dry process kilns were developed in the late 19th century, and wet process kilns became dominant in subsequent periods. In the 1960s, the suspension preheater (SP) process, part of the dry process, was imported from Germany and, due to its high energy efficiency, SP kilns gained in popularity and took a dominant position. Most of the newly built kilns in the 1960s were SP kilns and, in the 1970s, continuing improvements were made by Japanese companies, and new suspension preheater (hereinafter

\footnotetext{
${ }^{2}$ More precisely, there are also semi-dry and semi-wet process kilns. See Shimoda (2016).
} 
NSP) kilns were developed. In our data, from 1970 to 1995, almost all newly built kilns were NSP kilns, and this homogeneity of investment simplifies our analysis; the firms simply chose an amount of investment rather than types of investment.

\subsection{The Japanese Cement Industry}

This section aims to provide the historical background of the capacity coordination policies, as well as describing these policies in detail. Table A1, a chronological table, in Appendix, which summarizes the historical events that were related to capacity coordination policies, may help you read through this section.

\subsubsection{Historical Background and Excess Capacity}

The cement industry in Japan, which dates back to the late 19th century, grew rapidly with the recovery and high growth of the Japanese economy from the late 1940s to the early 1970s. In the period of economic recovery between 1946 and 1954, there was an urgent need to reconstruct the infrastructure and buildings damaged during World War II. In addition, in the so-called high growth period between 1955 and 1973, further investment in infrastructure, such as roads, sea ports, and dams was necessary. These construction investments generated vast demand for cement. Panel (a) of Figure 1 illustrates the demand for and supply of cement in Japan. As shown in the figure, domestic sales of cement, denoted by the dashed line, increased sharply until 1973, when the first oil crisis occurred, and demand was met by domestic production, denoted by the solid line. As summarized in Panel (b) of Figure 1, new entries took place mainly from the late 1950s to the early 1960s, as the number of cement firms increased from 17 in 1954 to 24 in $1964 .^{3}$ Furthermore, the number of plants and kilns increased in tandem with the new entries and continued to increase until the late 1960s, when the new entries of firms ceased. The production capacity of the industry increased even more rapidly in the 1950s and 1960s, as denoted by the solid line in Panel (c) of Figure 1.

The first oil crisis in 1973 was a turning point for the postwar Japanese economy. In 1974, the growth rate of real GDP became negative for the first time in the postwar period and put an end to the high growth of previous decades. In the 1950s and 1960s, the Japanese economy had continued growth at around $10 \%$ per year, but after the first

\footnotetext{
${ }^{3}$ In this period, strong growth in the cement market induced new entries from related industries, such as coal, chemicals, iron, and steel (Wada, 1995).
} 
Figure 1: Industry Evolution over Time


Source: Japan Cement Association (1998), pp.117-119.

oil crisis the growth rate fell to $4-5 \%$. This slowdown in economic growth caused a decline in construction investment. Moreover, the increase in the cumulative government deficit and the effort toward fiscal reconstruction reduced public construction investment. This substantial decline in construction investment caused a decline in domestic 
demand for cement, as shown in Panel (a) of Figure 1. In addition, the second oil crisis occurred in 1979 and, afterward, excess capacity emerged in the cement industry. Though the demand for cement declined, production capacity was maintained or even increased slightly until 1985. ${ }^{4}$ Although the utilization rate of the equipment (production/capacity) was around $70-80 \%$ in the 1950s and 1960s, it fell below 70\% in the early 1970s and was consistently below $70 \%$ and sometimes fell below $60 \%$ in the late 1970 s, as in Panel (c) of Figure 1. To maintain profitability under a sharp increase in oil prices, the cement firms were allowed, three separate times, to organize a "recession cartel." ${ }^{5}$ Although these recession cartels raised the price of cement temporarily, they did not promote divestment of capacity, which led to further policy intervention—capacity coordination—by MITI.

\subsubsection{Capacity Coordination Policies}

As the cement industry and other industries-including electric furnace steelmaking and aluminium refining-faced excess capacity problems, the Japanese government arranged capacity coordination in each designated industry by organizing cartels ("instructed cartels") under the Temporary Law for Structural Improvement of the Special Industries (Tokutei Sangyō Kōzō Kaizen Rinji Sochi Hō). ${ }^{6}$ More precisely and legally speaking, the cement industry first submitted an application to MITI, which was approved in April 1984, and then MITI announced the "Basic Plan for Structural Improvement of the Cement Industry" in August 1984 (Japan Cement Association, ed, 1998: p.51) instructing the cement firms to organize a cartel in January 1985 (Cement Press ed. 1985, p.18) to implement the capacity reduction plan.

The plan consisted of two main components: capacity coordination and organization of firms into five groups to promote cooperation within the groups. Regarding capacity coordination, the plan prescribed that 30 million tons of the 129 million tons of exist-

\footnotetext{
${ }^{4}$ Some cement firms attempted to solve this issue by exporting cement to mainly South Korea, as plotted as a dotted line in Panel (a) of Figure 1. Note that, however, as opposed to Röller and Steen (2006) who study the Norwegian cement industry, the Japanese firms were not actively engaged in export, because cement is a heavy product and Japan is relatively far away from other countries, implying that the transportation costs can be a big burden for these firms.

${ }^{5}$ These cartels were approved by the Japan Fair Trade Commission under the Antitrust Law and the precise terms of the cartels were (1) November 11, 1975 to January 31, 1976, (2) June 24, 1977, to December 31, 1977, and (3) August 3, 1983, to December 31, 1983 (Japan Cement Association, ed, 1998: pp.49-50).

${ }^{6}$ Prior to this law, a similar law called "The Temporary Law for Stabilization of the Special Recession Industries” (Tokutei Fukyo Sangyō Antei Rinji Sochi Hō) was legislated in May 1978. Although the cement industry was not subject to this earlier law, many other industries that were subject to the Temporary Law for Structural Improvement of the Special Industries were also subject to the earlier law.
} 
ing capacity for cement clinker be scrapped. Of this 30 million tons, 25 million tons was from nonoperating equipment and 5 million tons was from operating equipment (Cement Press ed. 1985, pp.16-7). Moreover, the allotment of capacity reduction to each firm was decided through negotiation between the firms and MITI by January 1985 . The allotment is shown in Table 1 and indicates there was heterogeneity in divestment rates. The firms were required to dispose of their excess capacity according to the allotment by the end of March 1985 except for six operating kilns, and these six operating kilns were to be disposed of by the end of March 1986. To smooth the implementation of capacity coordination, 23 cement firms were organized into five groups, each of which established a new company for cooperative business within the group, such as consignment production, joint sales, and arrangement of transportation (Japan Cement Association, ed, 1998: p.51). ${ }^{7}$

To alleviate unequal allotment across the firms, monetary side-payments were introduced. On February 1, 1985, 22 cement firms concluded an agreement to divest cement kilns. This agreement included such items as the quantity of divestment for each firm, a reporting and auditing scheme, penalty charges for deficiency of divestment, sidepayment to adjust for divestment costs, and so on. The agreement had two supplementary agreements: one on auditing and one on side-payment. The side-payment scheme consists of subsidies and contributions. Each firm receives subsidies from the special account of the Japan Cement Association, and the subsidies were calculated by "Hourly production capacity of divested kilns (in tons) $\times 7200$ (annual operating hours) $\times 50$ JPY" for divested nonoperating kilns and "Hourly production capacity of divested kilns (in tons) $\times 7200$ (annual operating hours) $\times 100$ JPY" for divested operating kilns. Each firm also contributes a portion of the total subsidies to the special account according to the following "adjustment coefficient":

\section{Adjustment Coefficient ${ }_{i}$}

$=[$ (Average of clinker production shares from FY 1981 to 1984)

+ (The share of expected remaining production capacity after the capacity reduction in FY 1985)] $\times \frac{1}{2}$,

where FY denotes fiscal year. As described above, the side-payment scheme was not

\footnotetext{
${ }^{7}$ This grouping remained after the removal of the Temporary Law for Structural Improvement of the Special Industries (Japan Cement Association, ed, 1998: p.53).
} 
sponsored by the government. Although the government provided effectively no direct monetary support, it provided tax benefits for the divested capacity and working capital loans with low interest rates in return for their participation.

Note that the compensation firms received under the side-payments was very small compared to the price of clinker. To make this point clear, let us show a back-of-envelope calculation. The average price of clinker in early 80's was about 14,000 JPY per ton and our estimated price cost margin was about $25 \%$, implying that the per-ton profit of the cement to be around 3,500 JPY. However, based on the side-payment scheme, the firms could receive only 100 JPY for the operating kilns per ton (and even 50 JPY for the nonoperating kilns), which is very small compared to the per-ton profit. This per-ton profit calculation is based on a single year production amount and, as divestment is irreversible, the continuation value of capacity per ton would be much higher than this number. In Section 3.3, we discuss more about why such small subsidies were able to achieve the required divestment allocation.

Although the divestment plan was completed as scheduled, excess capacity remained. Thus, MITI again prepared a law for further capacity reduction, the Law for Facilitating Transformation of Industrial Structure (Sangyō Kōzō Tenkan Enkatsuka Rinji Sochi Hō) in April 1987. A divestment plan to scrap 10.7 million tons of operating capacity out of 98 million tons of existing capacity was authorized by MITI in December 1988, and this plan was completed by March 1991. At that time, however, because of an increase in demand under the "Heisei bubble" boom, cement firms experienced capacity shortages. Consequently, they applied to MITI to cancel their obligations under the law, which was approved in May 1991 (Japan Cement Association, ed, 1998: pp.52-3).

\subsection{Data Sources and Descriptive Statistics}

We manually collect the data from various issues of Cement Yearbook (Cement Nenkan), published by the Cement Press Co. Ltd. (Cement Shinbunsha), which is also used by Nishiwaki and Kwon (2013) and Nishiwaki (2016b). This yearbook provides plant-level information on monthly production capacity, production output (both clinker and cement), number of workers, number of kilns, size of individual kilns, kiln ownership, and the geographical location of the plants. In terms of geographical location, we divide the territory of Japan into eight areas, as in Nishiwaki (2016b). We obtain the price of gypsum from the Corporate Goods Price Index, published by the Bank of Japan. We use the price 
Table 1: Allotment of Capacity Reduction

\begin{tabular}{|c|c|c|c|c|c|c|c|}
\hline \multirow[b]{3}{*}{ Group } & \multirow[b]{3}{*}{ Firm } & \multicolumn{3}{|c|}{ 1st Policy Intervention } & \multicolumn{3}{|c|}{ 2nd Policy Intervention } \\
\hline & & \multirow{2}{*}{$\begin{array}{r}\text { Existing } \\
\text { Capacity }\end{array}$} & \multicolumn{2}{|c|}{ Reduction } & \multirow{2}{*}{$\begin{array}{r}\text { Existing } \\
\text { Capacity }\end{array}$} & \multicolumn{2}{|c|}{ Reduction } \\
\hline & & & Amount & $\%$ & & Amount & $\%$ \\
\hline \multirow[t]{6}{*}{1} & Onoda Cement & 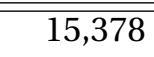 & $\overline{5,605}$ & $\overline{\overline{36.4}}$ & $\overline{9,840}$ & $\overline{7446}$ & $\overline{\overline{77.6}}$ \\
\hline & Mikawa Onoda Cement & & - & - & 360 & 0 & 0.0 \\
\hline & Hitachi Cement & 1,543 & 230 & 14.9 & 872 & 0 & 0.0 \\
\hline & Mitsui Kozan & 3,827 & 1,618 & 42.3 & 2,209 & 0 & 0.0 \\
\hline & Shin-Nittetsu Kagaku & 1,172 & 378 & 32.3 & 794 & 0 & 0.0 \\
\hline & Toyo Soda Kogyo & 4,134 & 906 & 21.9 & 3,228 & 0 & 0.0 \\
\hline \multirow[t]{4}{*}{2} & Nihon Cement & 17,967 & 4,936 & 27.5 & 13,031 & 1,555 & 11.9 \\
\hline & Myojo Cement & 3,150 & 699 & 22.2 & 2,451 & 0 & 0.0 \\
\hline & Daiichi Cement & 1,449 & 357 & 24.6 & 1,092 & 0 & 0.0 \\
\hline & Osaka Cement & 7,965 & 1,205 & 15.1 & 6,760 & 1,469 & 21.7 \\
\hline \multirow[t]{3}{*}{3} & Mitsubishi Kogyo Cement & 14,120 & 926 & 6.6 & 12,799 & 2,198 & 17.2 \\
\hline & Tokuyama Soda & 6,886 & 1,780 & 25.8 & 5,106 & 0 & 0.0 \\
\hline & Tohoku Kaihatsu & & 0 & 0 & 2,314 & 0 & 0.0 \\
\hline \multirow[t]{6}{*}{4} & Sumitomo Cement & 12,558 & 1,833 & 14.6 & 10,112 & 1,677 & 16.6 \\
\hline & Hachinohe Cement & 1,310 & 0 & 0 & 1,310 & 0 & 0.0 \\
\hline & Aso Cement & 1,672 & 356 & 21.3 & 1,316 & 0 & 0.0 \\
\hline & Karita Cement & 2,318 & 661 & 28.5 & 1,657 & 659 & 39.8 \\
\hline & Nittetsu Cement & 1,789 & 282 & 15.8 & 1,507 & 0 & 0.0 \\
\hline & Denki Kagaku Kogyo & 3,517 & 881 & 25 & 2,636 & 0 & 0.0 \\
\hline \multirow[t]{5}{*}{5} & Ube Kosan & 10,887 & 363 & 3.3 & 10,524 & 2,411 & 22.9 \\
\hline & Chichibu Cement & 10,797 & 5,020 & 46.5 & 5,777 & 0 & 0.0 \\
\hline & Tsuruga Cement & 1,893 & 248 & 13.1 & 1,645 & 0 & 0.0 \\
\hline & Ryukyu Cement & 690 & 150 & 21.7 & 540 & 0 & 0.0 \\
\hline & Total & 125,615 & 29,027 & 23.1 & 97,880 & 10,705 & 10.9 \\
\hline
\end{tabular}

Source: Cement Press (1989), p.47.

Note: The values in the third, fourth, sixth and seventh columns are measured in thousands of tons.

as an instrument when estimating the demand function in our empirical analysis.

Summary statistics of our data from 1970 to 1995 are given in Table 2. Panel (a) presents two firm-level statistics: the number of firms and the number of plants within a firm. The number of firms varies across the years in the sample, ranging from 20 to 24 because of some entries and exits, including several mergers and company splits, as shown in Figure 1. The number of plants within a firm varies substantially, ranging from 1 to 11 , which indicates there is heterogeneity in firm size. Panel (b) of Table 2 presents plantlevel statistics for 1970 and 1995, the start and end years of our sample. It is clear that the number of plants decreased from 54 to 40 during this period. Monthly capacity is defined as how much clinker a plant can produce when operating for 600 hours per month, and the utilization rate is defined as clinker production divided by annualized capacity. Both monthly capacity and annual production increased, but the growth rate of production was higher than that of monthly capacity, which resulted in a higher utilization rate in 
Table 2: Summary Statistics

\begin{tabular}{lrrrrr}
\hline & Num. of Obs. & Mean & Std. Dev. & Min & Max \\
\hline \hline Panel (a): Firm-Level Statistics & & & & & \\
$\quad$ \# of Firms & & - & - & 20 & 24 \\
\# of Plants within a Firm & & 2.50 & 1 & 1 & 11 \\
\hline Panel (b): Plant-Level Statistics & & & & & \\
In 1970 (beginning year) & 54 & 128,815 & 80,133 & 25,000 & 350,000 \\
$\quad$ Monthly Capacity (tons) & 54 & $1,031,160$ & 616,927 & 48,000 & $2,684,197$ \\
Annual Clinker Production (tons) & 54 & $69.1 \%$ & 20.7 & $9.3 \%$ & $115.3 \%$ \\
Utilization (\%) & 54 & 318.8 & 175.6 & 114 & 1205 \\
\# of Workers (person) & & & & & \\
In 1995 (last year) & 40 & 202,656 & 123,469 & 55,167 & 588,417 \\
Monthly Capacity (tons) & 40 & $2,227,377$ & $1,528,054$ & 616,784 & $7,405,758$ \\
Annual Clinker Production (tons) & 40 & $88.9 \%$ & 10.8 & $54.4 \%$ & $104.9 \%$ \\
Utilization (\%) & 40 & 145.2 & 67.0 & 51 & 399 \\
\# of Workers (person) & & & & & \\
\hline
\end{tabular}

1995. Note that the average utilization rate in 1970 was about $70 \%$, which is lower than our expectation, as it was prior to the first oil crisis and the Japanese economy was still experiencing high growth. We can also see a dramatic decrease in the number of workers: in 1970, the average number of workers was about 382, but in 1995 this had fallen to 145. This change indicates that there was substantial technological advancement in the form of automation and, consequently, labor productivity increased sharply.

\section{Empirical Analysis}

In order to comprehensively evaluate the series of capacity coordination policies, we examine the policy from two angles: the demand side and the supply side. Due to the potentially anti-competitive nature of this policy, we first ask whether this policy increased the market power of the firms and harmed consumer welfare in Subsection 3.1. Second, in Subsection 3.2, we ask whether the firms' divestment decisions were distorted by the policy and whether divested plants were inefficient not only from the viewpoint of an individual firm but also from the viewpoint of social welfare. After finishing our assessment of the policy, we come back in Subsection 3.3 to ask a more fundamental question of why firms did not divest their unused plants before the capacity coordination policies. 


\subsection{Impact on Prices and Markups}

As capacity coordination is often used for cartels and is viewed as an anti-competitive business practice, we first ask whether this policy increased the market power of the firms and harmed consumer welfare. In other words, we are interested in examining whether the policy distorted the functioning of the market. Figure 2 shows changes in the nominal national average price of Portland cement in Japan. This figure demonstrates that, although there were significant price increases during the three recession cartel periods in the 1970s and the early 1980s, which are denoted by the light gray shaded areas, there were no obvious price increases during the capacity coordination policy implementations, which are denoted by the dark gray shaded areas. Furthermore, we also conduct a reduced form analysis, regressing the regional prices on the dummy variables that indicate the periods of policy implementation and some other controls. The results summarized in Table A2 indicate that, regardless of the specifications, we cannot detect any statistically significant positive effects on the price. However, the existing literature, e.g., Kamita (2010) and Hampton and Sherstyuk (2012), points out that capacity coordination policies have pro-collusive effects, facilitating implicit or explicit collusion. To examine whether this policy also facilitated collusion, we focus on the markups charged by the firms, because markups are more suggestive of market power than prices, though there might be a limitation.

Empirical framework To recover the markups charged by the firms, we use a two-step method commonly used in the literature, including that used by Röller and Steen (2006) who study the Norwegian cement industry. In the first step, we specify and estimate the following demand function:

$$
\log \left(Q_{m t}\right)=\alpha \log \left(P_{m t}\right)+X_{m t}+\varepsilon_{m t}
$$

where $Q_{m t}$ and $P_{m t}$ are the total quantity produced and the price in region $m$ in a given year $t ; X_{m t}$ denotes region- and year-specific demand shifters; and $\varepsilon_{m t}$ is the regression error term. Note that the unit of observation here is a combination of year and region. The use of this log-log specification for cement demand can be also found in Ryan (2012). To address the simultaneity bias, we take an instrumental variable approach using the price of gypsum and the regional-level price of limestone, as well as the regional-level 
Figure 2: Transition of the Nominal Portland Cement Price in Japan

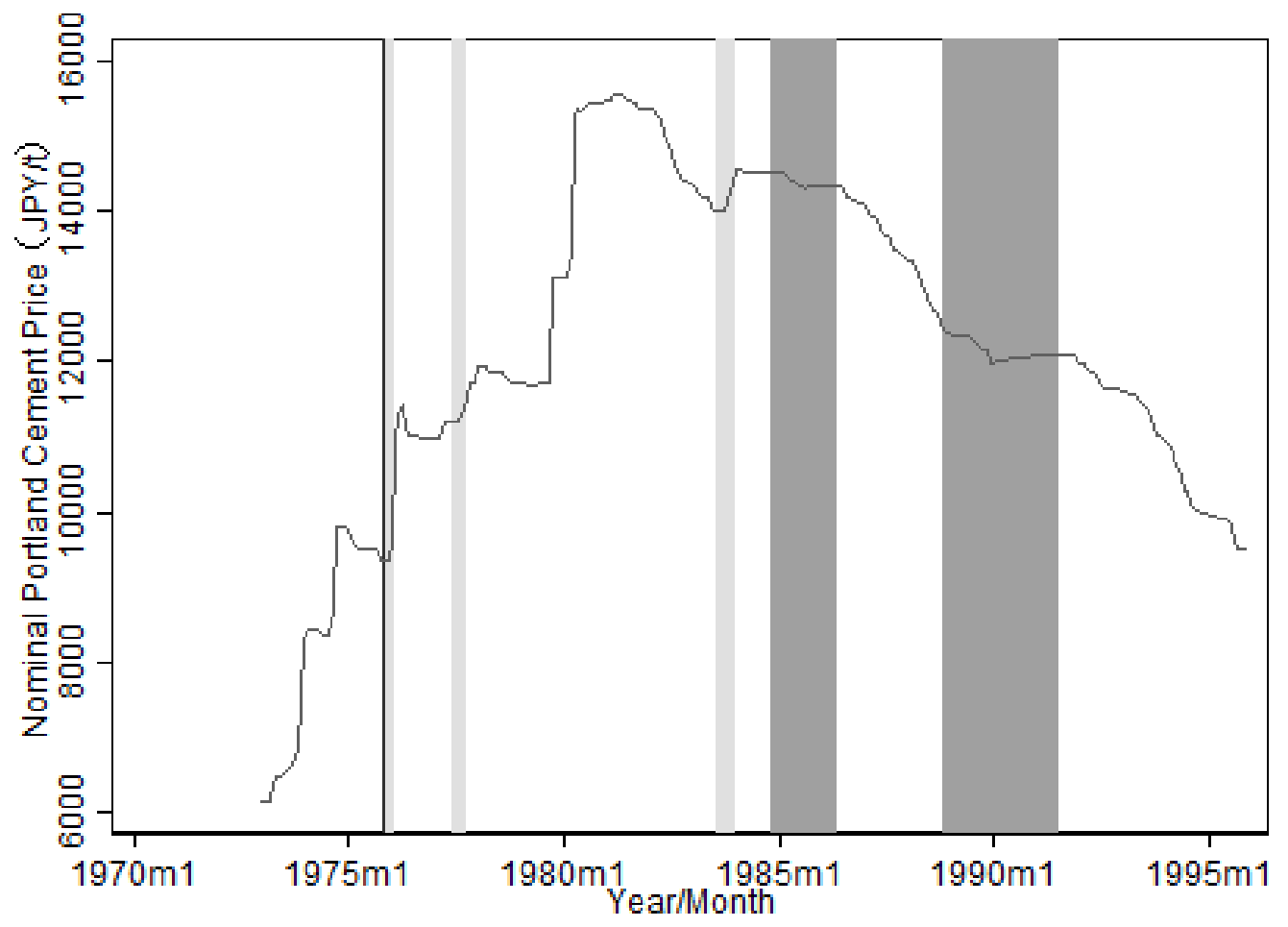

Note: The first three light gray shaded areas represent the recession cartel formation periods, whereas the last two dark gray shaded areas represent the periods when the capacity coordination policies were implemented.

real wages as instruments, which are intermediate inputs as explained in Section $2 .^{8}$

The second step relies on microeconomic theory. Assuming that the firms compete in quantity, we can use the first-order conditions with respect to the quantity, which gives us the following equation:

$$
\frac{\partial \pi_{f m t}}{\partial q_{f m t}}=P_{m t}+\frac{\partial P_{m t}}{\partial Q_{m t}} q_{f m t}-\frac{\partial c\left(q_{f m t}\right)}{\partial q_{f m t}}=0
$$

where $\pi_{f m t}$ and $q_{f m t}$ are the profit and production of firm $f$ operating in region $m$ at time $t$, respectively, and $c(\cdot)$ is a cost function. Note that, if a firm owns more than one plant in a given region, we aggregate them to obtain $q_{f m t}$, because each firm jointly decides the quantity in a given region across plants. On the right-hand side of the equation, the sum of the first two terms represents the marginal revenue, whereas the last term is the

\footnotetext{
${ }^{8}$ Though fuel is one of the most important inputs for producing cement, we do not include the oil prices as instruments. This is largely because the regional variations in the fuel prices are effectively zero in Japan for geographical reasons and even if there are tiny variations, such a regional difference is relatively persistent, which means that the effects would be captured by the region fixed effects. In fact, the oil prices do not exhibit any statistically significant effects when included as an instrument in the first-stage regression.
} 
marginal cost, which we want to recover. In the data, we directly observe $P_{m t}, Q_{m t}$ and $q_{f m t}$. Moreover, as the estimates of $\alpha$ are elasticities of demand, we can rewrite $\frac{\partial P_{m t}}{\partial Q_{m t}}$ using $\alpha, P_{m t}$, and $Q_{m t}$ :

$$
\frac{\partial P_{m t}}{\partial Q_{m t}} / \frac{P_{m t}}{Q_{m t}}=\frac{1}{\alpha}
$$

which means that, knowing $\alpha, P_{m t}$, and $Q_{m t}$, we can obtain the marginal cost. Once we have the marginal costs, we can easily calculate the markups as a function of $\alpha, q_{f m t}$, and $Q_{m t}$ :

$$
\frac{P_{m t}-m c}{P_{m t}}=-\frac{1}{\alpha} \frac{q_{f m t}}{Q_{m t}} .
$$

One might worry that, due to the collusive nature of the industry, the first order conditions might not hold. In order to check the robustness of our results, therefore, we allow for the possibility that the firms engage in collusion via proportional reduction when they collude.

Here we assume that the cement firms engage in Cournot competition. Alternatively, we could use models proposed by Bresnahan (1982), Lau (1982), and Steen and Salvanes (1999) which allow for more flexible modes of competition. However, we take our approach because our focus is not to identify the mode of competition. Rather we focus on examining the change in markups given the mode of competition. Nonetheless, we estimate a model similar to Bresnahan (1982) and Lau (1982) and show that our subsequent results are robust to such modeling choices. We discuss this issue and show the estimation results in Appendix D.

Estimation results and recovered markups Table 3 shows the estimation results for the demand function. Ideally, we want to include the year fixed effects in the demand equation (1). Unfortunately, regional level gypsum prices are not available. Hence we only observe a national-level gypsum price in a given year, and we cannot exploit variation in gypsum prices across regions. On the other hand, there are regional variations in the limestone price and real wage. Nonetheless, we believe that it is important to include all three variables as instruments to guarantee the validity of the first stage regression in the demand estimation. Thus, instead of including the year fixed effects, we control for the year effects using a flexible polynomial function of year. ${ }^{9}$ The table contains the

\footnotetext{
${ }^{9}$ Relatedly, the previous literature finds that import and export competition are important factors for demand estimation in the cement industry. We believe that the flexible polynomial function of year partly controls for such factors. Explicitly including real exchange rates for geographically close countries, Korea and Taiwan, does not qualitatively change any of the results.
} 
Table 3: Demand Function Estimation

\begin{tabular}{|c|c|c|c|c|c|c|c|}
\hline \multirow[b]{2}{*}{ Dependent Var. } & \multirow{2}{*}{$\begin{array}{l}\text { Model (i) } \\
\text { OLS } \\
\text { 4th Order } \\
\quad \log (Q)\end{array}$} & \multicolumn{2}{|c|}{$\begin{array}{l}\text { Model (ii) } \\
\text { IV } \\
\text { 2nd-Order }\end{array}$} & \multicolumn{2}{|c|}{$\begin{array}{l}\text { Model (iii) } \\
\text { IV } \\
\text { 3rd-Order }\end{array}$} & \multicolumn{2}{|c|}{$\begin{array}{l}\text { Model (iv) } \\
\text { IV } \\
\text { 4th-Order }\end{array}$} \\
\hline & & $\begin{array}{c}\text { 1st } \\
\log (P)\end{array}$ & $\begin{array}{c}\text { 2nd } \\
\log (Q)\end{array}$ & $\begin{array}{c}\text { 1st } \\
\log (P)\end{array}$ & $\begin{array}{c}\text { 2nd } \\
\log (Q)\end{array}$ & $\begin{array}{c}\text { 1st } \\
\log (P)\end{array}$ & $\begin{array}{c}\text { 2nd } \\
\log (Q)\end{array}$ \\
\hline $\log \left(P_{m t}\right)$ & $\begin{array}{l}-.07 \\
(.17)\end{array}$ & & $\begin{array}{c}-3.16^{* * *} \\
(0.82)\end{array}$ & & $\begin{array}{c}-1.06^{* * *} \\
(.31)\end{array}$ & & $\begin{array}{c}-1.30^{* * *} \\
(.34)\end{array}$ \\
\hline Controls & & & & & & & \\
\hline Year & $\begin{array}{l}-.04 \\
(.07)\end{array}$ & $\begin{array}{l}.02 \\
(.02)\end{array}$ & $\begin{array}{c}.17^{* * *} \\
(.05)\end{array}$ & $\begin{array}{l}.00 \\
(.03)\end{array}$ & $\begin{array}{l}-.00 \\
(.05)\end{array}$ & $\begin{array}{l}-.00 \\
(.01)\end{array}$ & $\begin{array}{l}.04 \\
(.07)\end{array}$ \\
\hline Year $^{2}$ & $\begin{array}{c}-.16^{* * *} \\
(.06)\end{array}$ & $\begin{array}{c}-.15^{* * *} \\
(.01)\end{array}$ & $\begin{array}{c}-.48^{* * *} \\
(.14)\end{array}$ & $\begin{array}{c}-.23^{* * *} \\
(.03)\end{array}$ & $\begin{array}{c}-.35^{* * *} \\
(.07)\end{array}$ & $\begin{array}{c}-.24^{* * *} \\
(.02)\end{array}$ & $\begin{array}{c}-.40^{* * *} \\
(.09)\end{array}$ \\
\hline Year $^{3}$ & $\begin{array}{c}.12^{* * *} \\
(.06)\end{array}$ & & & $\begin{array}{c}.05^{* * *} \\
(.01)\end{array}$ & $\begin{array}{l}.13^{* * *} \\
(.03)\end{array}$ & $\begin{array}{l}.06^{* *} \\
(.02)\end{array}$ & $\begin{array}{l}.08 \\
(.07)\end{array}$ \\
\hline Year $^{4}$ & $\begin{array}{l}-.00 \\
(.02)\end{array}$ & & & & & $\begin{array}{l}-.01 \\
(.01)\end{array}$ & $\begin{array}{l}.02 \\
.02\end{array}$ \\
\hline $\begin{array}{l}\text { Instrument Used } \\
\log \left(\text { Gypsum Price }_{t}\right)\end{array}$ & & $\begin{array}{c}.021^{* *} \\
(.01)\end{array}$ & & $\begin{array}{c}.05^{* * *} \\
(.01)\end{array}$ & & $\begin{array}{c}.06^{* * *} \\
(.02)\end{array}$ & \\
\hline $\log \left(\right.$ Limestone $\left._{m t}\right)$ & & $\begin{array}{c}.081^{* *} \\
(.01)\end{array}$ & & $\begin{array}{l}.04 \\
(.03)\end{array}$ & & $\begin{array}{l}.03 \\
(.03)\end{array}$ & \\
\hline $\log \left(\right.$ Wage $\left._{m t}\right)$ & & $\begin{array}{c}.023^{*} \\
(.01) \\
\end{array}$ & & $\begin{array}{l}.04 \\
(.04) \\
\end{array}$ & & $\begin{array}{l}.04 \\
(.04) \\
\end{array}$ & \\
\hline Fixed Effects & & & & & & & \\
\hline $\begin{array}{l}\text { Area Fixed Effects } \\
\text { F-test }\end{array}$ & $\begin{array}{l}\sqrt{ } \\
-\end{array}$ & $\begin{array}{c}\sqrt{ } \\
4.82^{* *}\end{array}$ & $\begin{array}{l}\sqrt{ } \\
-\end{array}$ & $\begin{array}{c}\sqrt{ } \\
22.3^{* * *}\end{array}$ & $\begin{array}{l}\sqrt{ } \\
-\end{array}$ & $\begin{array}{l}\sqrt{ } \\
17.2^{* * *}\end{array}$ & $\begin{array}{l}\sqrt{ } \\
-\end{array}$ \\
\hline $\mathrm{N}$ & 184 & 176 & 176 & 176 & 176 & 176 & 176 \\
\hline
\end{tabular}

Note: Significance levels are denoted by $<0.10\left(^{*}\right),<0.05\left({ }^{* *}\right)$, and $<0.01\left({ }^{* *}\right)$. The numbers in parentheses show the standard errors, which are clustered at the area level.

results for four different specifications. The first column, labeled Model (i), shows the regression results without using any instruments. The rest of the specifications use an instrument, but the flexibility of year is slightly different in each case: the second-order, third-order or fourth-order polynomials. As expected, the estimated price coefficient using OLS is higher than those of other specifications, indicating that Model (i) suffers from upward bias, due to simultaneity. Thus, we use an instrumental variable approach to estimate the demand and show both the first- and second-stage estimation results for Models (ii), (iii), and (iv). For each model, we demonstrate the first stage regressions under the columns of $\log (P)$, whereas the results for the second stage regressions are demonstrated under the columns of $\log (Q)$. The results for the first stage regressions enable us to confirm that the gypsum price is indeed a valid instrument. Although Models (ii) to (iv) provide similar qualitative results, the magnitude of the price coefficient in Model (ii) is slightly different from those of Models (iii) and (iv). We believe that this dis- 
crepancy reflects the time trend of price, because the trend in price movement is inverseU shaped but not exactly symmetric as in Figure 2 . Alternatively, we could include year fixed effects. The estimated price coefficient is -2.75 , which is in between Model (ii) and Model (iii), with 10 percent significance. However, a large portion of the variation in the data is absorbed by the year fixed effects, resulting in a small F-statistics in the first stage. Therefore, in the rest of the analyses, we use the estimates of Models (ii), (iii), and (vi).

Note that the existing literature, such as Miller and Osborne (2014) and Salvo (2010), discusses spatial differentiation in the cement industry, casting a doubt on our market definition, which is based on administrative boundaries. Our regional-level demand analysis here implicitly assumes that there is no cement transportation across regions, i.e., cement was consumed within in each region. However, this assumption might be violated. We believe that it is not a serious concern, because, when re-doing the same empirical analysis using only eastern part of Japan where cement transportation is less common, we obtain the same results, qualitatively and quantitatively.

Table 4: Markups Charged by the Firms

\begin{tabular}{|c|c|c|c|c|c|c|}
\hline \multicolumn{7}{|c|}{ Panel (a): Summary Statistics for Recovered Markups } \\
\hline \multirow{4}{*}{$\begin{array}{l}\text { Average Markup } \\
\text { Median Markup }\end{array}$} & \multicolumn{2}{|c|}{ Model (ii) } & \multicolumn{2}{|c|}{ Model (iii) } & \multicolumn{2}{|c|}{ Model (vi) } \\
\hline & Ind. Firm & Group & Ind. Firm & Group & Ind. Firm & Group \\
\hline & $8.1 \%$ & $10.3 \%$ & $24.2 \%$ & $30.8 \%$ & $19.8 \%$ & $25.2 \%$ \\
\hline & $6.1 \%$ & $8.7 \%$ & $18.3 \%$ & $26.1 \%$ & $15.0 \%$ & $21.4 \%$ \\
\hline \multicolumn{7}{|c|}{ Panel (b): Markup Regression Results } \\
\hline & \multicolumn{2}{|c|}{ Model (ii) } & \multicolumn{2}{|c|}{ Model (iii) } & \multicolumn{2}{|c|}{ Model (vi) } \\
\hline & Ind. Firm & Group & Ind. Firm & Group & Ind. Firm & Group \\
\hline \multirow[t]{2}{*}{ 1985/1986 Dummy } & .000 & .000 & .001 & .001 & .001 & .001 \\
\hline & $(.001)$ & $(.001)$ & $(.002)$ & $(.002)$ & $(.001)$ & $(.0022)$ \\
\hline \multirow[t]{2}{*}{ 1988/1990 Dummy } & .001 & -.001 & .002 & -.002 & .002 & -.001 \\
\hline & $(.001)$ & $(.001)$ & $(.004)$ & $(.004)$ & $(.003)$ & $(.0033)$ \\
\hline Year up to 4 th & $\sqrt{ }$ & $\sqrt{ }$ & $\sqrt{ }$ & $\sqrt{ }$ & $\sqrt{ }$ & $\sqrt{ }$ \\
\hline Firm Fixed Effects & $\sqrt{ }$ & $\sqrt{ }$ & $\sqrt{ }$ & $\sqrt{ }$ & $\sqrt{ }$ & $\sqrt{ }$ \\
\hline Area Fixed Effects & $\sqrt{ }$ & $\sqrt{ }$ & $\sqrt{ }$ & $\sqrt{ }$ & $\sqrt{ }$ & $\sqrt{ }$ \\
\hline Num. of Obs. & 829 & 829 & 829 & 829 & 829 & 829 \\
\hline $\operatorname{Adj} R^{2}$ & .643 & .828 & .643 & .828 & .643 & .828 \\
\hline
\end{tabular}

Note: Panel (a) shows the average and median markups for three different specifications, corresponding to models (ii), (iii) and (iv) in Table 3. Panel (b) shows the results for the following regression:

$$
\operatorname{Markup}_{m t}=\gamma_{0}+\gamma_{1} \mathbf{1}_{\{t=1985,1986\}}+\gamma_{2} \mathbf{1}_{\{t=1988,1989,1990\}}+\text { Controls }+\varepsilon_{m t} .
$$

Significance levels are denoted by $<0.10\left({ }^{*}\right),<0.05\left({ }^{* *}\right)$, and $<0.01(* *)$. The numbers in parentheses show the standard errors, clustered at the firm-level or group-level.

Using the estimated demand elasticity coefficients and equation (3), we recover the markups for the firms. The markups over years are given in Figure 3 and the summary statistics are given in Panel (a) in Table 4. Panels (a) and (b) in Figure 3 correspond to the 
markups recovered by Models (iii) and (iv) in Table 3, whereas the three specifications of Panel (b) in Table 4 correspond to the three different elasticities estimated by Models (ii), (iii), and (iv) in Table 3. Moreover, in Panel (b) in Table 4, the results in the first, third, and fifth columns assume that each individual firm maximizes its own profit, whereas the results in the second, fourth, and sixth columns assume that each group of firms maximizes its joint profit. As explained in Section 2, when MITI initiated this capacity coordination policy, the firms were categorized into five groups and the firms in a given group could cooperate to some extent. Thus, to capture such effects and to check robustness, we also estimate the model assuming that each group maximizes its joint profit. In terms of the estimation results, again, although Models (ii), (iii), and (iv) provide similar qualitative results, the magnitude in Model (ii) is quite different from those in Models (iii) and (iv): Model (ii) gives us about $8 \%$ to $10 \%$ markups on average, whereas Models (iii) and (vi) give us around $20 \%$ to $30 \%$ markups. Inclusion of the higher order terms of year effects does not change our quantitative results from those in Models (iii) and (vi). Given that cement is a typical process industry with high fixed costs, we believe that relatively large markups in Models (iii) and (vi) seem more realistic than the estimates in Model (ii). Moreover, when assuming joint profit maximization, both the average and median markups are higher than those with assumed individual profit maximization. Theoretically speaking, in order to rationalize the observed price, marginal costs under joint profit maximization must be estimated to be lower than marginal costs under individual profit maximization, which predicts that we would find higher markups under the joint profit maximization assumption and is verified in our results.

Did the firms gain market power? Next, to investigate whether the policy increased markups for the firms, we regress the markups charged by firm $j$ in market $m$ in year $t$ on the indicator variables for 1985/1986 and 1988/1990:

$$
\text { Markup }_{j m t}=\gamma_{0}+\gamma_{1} \mathbf{1}_{\{t=1985,1986\}}+\gamma_{2} \mathbf{1}_{\{t=1988,1989,1990\}}+F_{m}+F_{f}+\varepsilon_{m t},
$$

including the firm- and market-fixed effects. If the markups charged by the firms increased during the periods when the policies were active, the estimated coefficients for these indicator variables, namely $\gamma_{1}$ and $\gamma_{2}$, should be positive. The estimation results are summarized in Panel (b) of Table 4. Again, we use three different demand specifications to check the robustness of our results, corresponding to models (ii), (iii), and (vi) in 
Table 3. The first, third, and fifth columns in Panel (b) present the results, assuming that each individual firm maximizes its own profit, whereas the results in the second, fourth, and sixth columns assume that each group of firms maximizes its joint profit. Regardless of the specifications under the label of "Ind. Firm," the coefficients for the indicator variables of 1985/1986 and 1988/1990 are not statistically significant, means that we do not find any evidence that the policy increased the markups. Our results are robust even if we assume that each group jointly decided their production quantities. Therefore, we conclude that the evidence is consistent with the view that the markup charged by the cement firms did not increase during the periods of policy implementation.

Estimation results: Impacts on plant utilization How are these results possible? The reason the coefficients for the 1985/1986 dummies are insignificant might be that most of the scrapped capacity during the first capacity coordination policy was nonoperating capacity. Thus, even though the firms shut down these plants, the market power of the firms was unaffected. However, if this explanation is true, we cannot explain why the 1988/1990 dummy has no impact on markups. The second capacity coordination policy in fact forced the firms to shut down some operating plants, and thus, demand would most likely have exceeded supply (production capacity), which must have given firms market power.

To investigate why the firms did not experience an increase in market power during the second policy intervention, we hypothesize that demand did not exceed production capacity. As plant utilization rates were relatively low prior to the second policy intervention, the firms were able to concentrate production in the remaining efficient plants and meet the demand by fully utilizing these plants. Motivated by this hypothesis, we regress utilization rates on the indicator variables for 1985/1986 and 1988/1990, and the results are presented in Table 5. We control for year effects through polynomial approximation in Specifications (i) and (iii), and through year fixed effects in Specifications (ii) and (vi). The estimation results are consistent with our expectations and support our hypothesis. Regardless of the specifications, positive and statistically significant coefficients on the 1988/1990 dummy variable indicate that the firms increased the utilization rates of their remaining plants to meet demand during the second policy intervention. Our hypothesis is also supported by Figure 3 and Panel (c) of Figure 1. We can clearly see that the price-cost margins do not change during the policy implementations in Figure 3 and that the firms met demand exactly by fully utilizing their remaining production facilities 
Figure 3: Price-Cost Margin

\section{Estimated Markups by Year}

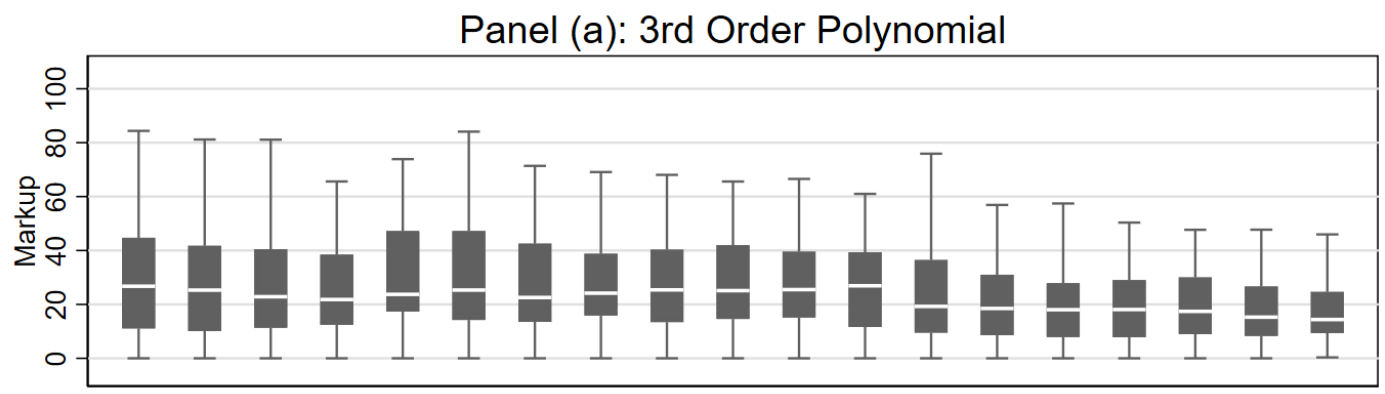

1976197719781979198019811982198319841985198619871988198919901991199219931994 excludes outside values

Panel (b): 4th Order Polynomial

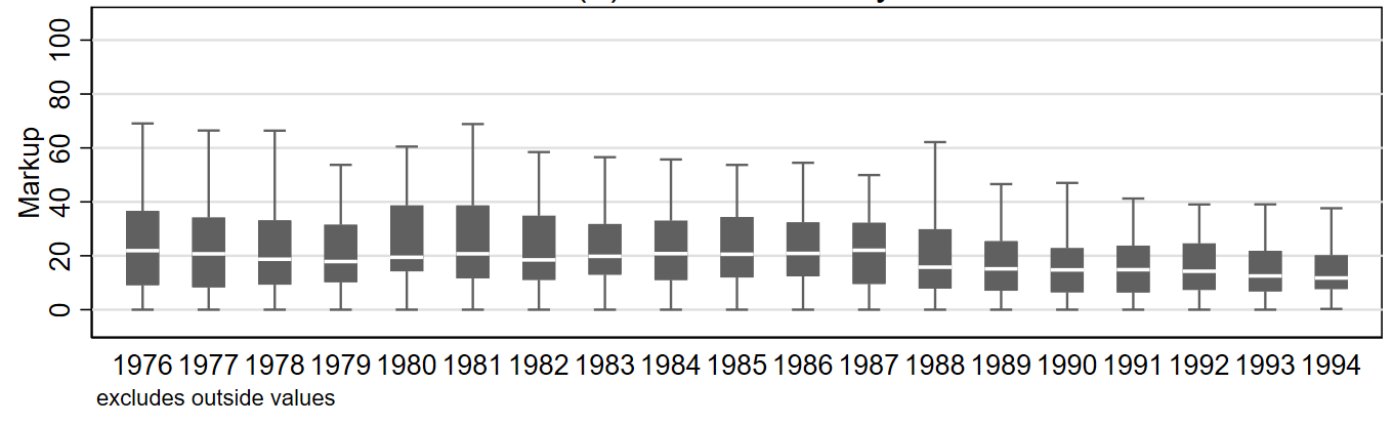

Table 5: Plant-Level Utilization Rate and Policy Interventions

\begin{tabular}{lcccc}
\hline & $\begin{array}{c}\text { (i) } \\
\text { Utilization }\end{array}$ & $\begin{array}{c}\text { (ii) } \\
\text { Utilization }\end{array}$ & $\begin{array}{c}\text { (iii) } \\
\text { Utilization }\end{array}$ & $\begin{array}{c}\text { (vi) } \\
\text { Utilization }\end{array}$ \\
\hline \hline $1985 / 1986$ Dummy & 1.974 & -3.979 & 1.574 & $-4.841^{*}$ \\
& $(1.725)$ & $(3.747)$ & $(1.776)$ & $(3.884)$ \\
$1988 / 1990$ Dummy & $5.798^{* * *}$ & $14.666^{* * *}$ & $5.613^{* * *}$ & $13.881^{* * *}$ \\
& $(1.393)$ & $(3.224)$ & $(1.420)$ & $(3.315)$ \\
Year up to 4th & $\sqrt{ }$ & & $\sqrt{ }$ & \\
Year Fixed Effects & & $\sqrt{ }$ & & $\sqrt{ }$ \\
Area Fixed Effects & $\sqrt{ }$ & $\sqrt{ }$ & $\sqrt{ }$ & $\sqrt{ }$ \\
Firm Fixed Effects & $\sqrt{ }$ & $\sqrt{ }$ & $\sqrt{ }$ & $\sqrt{ }$ \\
Plant Fixed Effects & & & $\sqrt{ }$ & $\sqrt{ }$ \\
\hline Num. of Obs. & 1,206 & 1,206 & 1,206 & 1,206 \\
Adj R $\mathrm{R}^{2}$ & .280 & .329 & .498 & .598 \\
\hline
\end{tabular}

Note: Significance levels are denoted by $<0.10\left({ }^{*}\right),<0.05\left({ }^{* *}\right)$, and $<0.01\left(^{* * *}\right)$. The numbers in parentheses show the standard errors, which are clustered at the firm-level.

\section{in Panel (c) of Figure 1.}


Robustness check: Collusion in the industry As pointed out by Nishiwaki (2016a), collusion among Japanese cement firms was prevalent in the 1970s and 1980s. Thus, our assumption that the firms played a Cournot game and competitively chose their quantities could be flawed and, as a result, our recovered marginal costs might be biased. In order to address this concern, we consider a case where the firms colluded throughout our sample period, assuming that they used one of the common cartel practices, called "proportional reduction" - the firms reduce their output proportionately from a benchmark output—which is studied by Shcherbakov and Wakamori (2017). We believe that our choice of proportional reduction assumption is appropriate in this context, because the cement firms indeed used this proportional reduction collusive technique when they were allowed to form recession cartels in the 1970s and the 1980s.

Under the proportional reduction assumption, the first-order conditions in equation (2) would not be satisfied with the observed quantity and prices. However, thanks to our proportional reduction assumption, we can still recover the first-order conditions using adjusted quantities and prices. To make this statement clear, consider a case where every firm reduces its output by $5 \%$ from the Cournot quantity, i.e., $q_{j}^{\text {Observed }}=0.95 q_{j}^{\text {Cournot }}$. Here, we choose $5 \%$ because it is the actual reduction percentage implemented during the recession cartel mentioned in Subsection 2.2.1. Now the observed quantities, $q_{j}^{\text {Observed }}$, and the observed price, $P\left(\sum_{j} q_{j}^{\text {Observed }}\right)$, would no longer satisfy the first-order conditions, but the inflated quantities, $q_{j}^{\text {Observed }} / 0.95$, which are equivalent to the Cournot quantity, and the deflated price, $P\left(\sum_{j} q_{j}^{\text {Observed }} / 0.95\right)$, would. In other words, the following recovered first-order conditions must be satisfied:

$$
\frac{\partial c\left(q_{f m t}\right)}{\partial q_{f m t}}=P_{m t}\left(\sum_{j} \frac{q_{j}^{\text {Observed }}}{0.95}\right)+\frac{\partial P_{m t}}{\partial Q_{m t}} \frac{q_{j}^{\text {Observed }}}{0.95} .
$$

The estimation results, based on these recovered first-order conditions, are demonstrated in Table 6. The format of this table is exactly the same as Table 4, i.e., Panel (a) shows the average and median markups, and Panel (b) shows the regression results whether the markups were increased during the periods of policy implementation. Again, there are three models, corresponding to the specifications in Table 3, and each model has two columns, assuming each individual firm maximizes its profit and each group of firms maximizes its joint profit. Regardless of the models and assumptions, the results are essentially the same as in Table 4 , both qualitatively and quantitatively. Pairwise comparisons between Tables 4 and 6 enable us to see that the markups under joint 
Table 6: Robustness: Markups Charged by the Firms

\begin{tabular}{|c|c|c|c|c|c|c|}
\hline \multicolumn{7}{|c|}{ Panel (a): Summary Statistics for Recovered Markups } \\
\hline \multirow{4}{*}{$\begin{array}{l}\text { Average Markup } \\
\text { Median Markup }\end{array}$} & \multicolumn{2}{|c|}{ Model (ii) } & \multicolumn{2}{|c|}{ Model (iii) } & \multicolumn{2}{|c|}{ Model (vi) } \\
\hline & Ind. Firm & Group & Ind. Firm & Group & Ind. Firm & Group \\
\hline & $9.9 \%$ & $12.3 \%$ & $29.5 \%$ & $36.7 \%$ & $24.1 \%$ & $30.1 \%$ \\
\hline & $7.9 \%$ & $10.8 \%$ & $23.5 \%$ & $32.2 \%$ & $19.2 \%$ & $26.4 \%$ \\
\hline \multicolumn{7}{|c|}{ Panel (b): Markup Regression Results } \\
\hline & \multicolumn{2}{|c|}{ Model (ii) } & \multicolumn{2}{|c|}{ Model (iii) } & \multicolumn{2}{|c|}{ Model (vi) } \\
\hline \multirow{3}{*}{ 1985/1986 Dummy } & Ind. Firm & Group & Ind. Firm & Group & Ind. Firm & Group \\
\hline & .000 & $\begin{array}{c}-.000 \\
0\end{array}$ & .001 & $\begin{array}{c}.001 \\
-1\end{array}$ & .001 & -.001 \\
\hline & $(.001)$ & $(.001)$ & $(.002)$ & $(.002)$ & $(.002)$ & $(.002)$ \\
\hline \multirow[t]{2}{*}{ 1988/1990 Dummy } & .001 & -.000 & .003 & -.000 & .002 & -.000 \\
\hline & $(.001)$ & $(.001)$ & $(.004)$ & (.004) & $(.003)$ & $(.003)$ \\
\hline Year up to 4 th & $\sqrt{ }$ & $\sqrt{ }$ & $\sqrt{ }$ & $\sqrt{ }$ & $\sqrt{ }$ & $\sqrt{ }$ \\
\hline Firm Fixed Effects & $\sqrt{ }$ & $\sqrt{ }$ & $\sqrt{ }$ & $\sqrt{ }$ & $\sqrt{ }$ & $\sqrt{ }$ \\
\hline Area Fixed Effects & $\sqrt{ }$ & $\sqrt{ }$ & $\sqrt{ }$ & $\sqrt{ }$ & $\sqrt{ }$ & $\sqrt{ }$ \\
\hline Num. of Obs. & 940 & 940 & 940 & 940 & 940 & 940 \\
\hline $\operatorname{Adj} R^{2}$ & .656 & .839 & .656 & .839 & .656 & .839 \\
\hline
\end{tabular}

Note: Panel (a) shows the average and median markups for three different specifications, corresponding to models (ii), (iii) and (iv) in Table 3. Panel (b) shows the results for the following regression:

$$
\text { Markup }_{m t}=\gamma_{0}+\gamma_{1} \mathbf{1}_{\{t=1985,1986\}}+\gamma_{2} \mathbf{1}_{\{t=1988,1989,1990\}}+\text { Controls }+\varepsilon_{m t} .
$$

Significance levels are denoted by $<0.10\left(^{*}\right),<0.05\left({ }^{* *}\right)$, and $<0.01\left(^{* * *}\right)$. The numbers in parentheses show the standard errors, clustered at the firm-level or group-level.

profit maximization are consistently higher, which also validates our results. Lastly, we would like to emphasize one caveat; as we assume that the firms were competitive in the previous analysis and the firms always colluded in this robustness check, the results demonstrated here could be seen as lower and upper bounds and true markups would be probably in between.

We believe that our analysis here is also robust to collusion in the downstream market, such as the concrete and/or construction industries, as long as these downstream firms are not vertically integrated with the cement firms. Even though some cement firms were indeed integrated with some downstream firms in the concrete industry, the majority of the downstream firms were not integrated with the cement firms, which implies that such a concern has a limited impact on our analysis. Therefore, based on our analysis, we conclude that the policy interventions did not have any significant impact on the markups charged by the firms. In other words, the policy successfully accelerated the capital adjustment process without lowering consumer welfare. As a corollary, if the government reduced production capacity a little bit more, then there would be excess demand, which would possibly increase the market power of the firms because the utilization rate was close to $100 \%$. Therefore, the amount of capacity reduction was key to 
the success of the policy, and we discuss this issue further in Section 4.

\subsection{Which plants were divested?}

Turning to the supply side, we first address the question of which plants were divested during the policy implementation. Given the allotment and relatively short time-frame, the firms might have shut down the plants that were relatively efficient. Thus, we first ask whether the individual firm's divestment decision was distorted by the policy interventions. Das (1992) asks a similar question in the context of the US cement industry, for which it builds and estimates a structural model of kiln divestment. As in Das (1992), a reasonable model of divestment would predict that the firms divest from the least productive kiln without strategic interactions. Still, we examine whether this prediction holds in this particular setting or whether the policy even distorts the firms' cost minimization.

At the same time, it is important to know whether the divested plants were also inefficient from a viewpoint of social welfare. With strategic interactions, even a simple model no longer guarantees that the firms' divestment decision is aligned with social cost minimization. The effectiveness of the policy crucially depends on whether the policy distorts divestment allocation across firms from the social cost minimization point of view. The goal of this subsection is to answer these two questions.

These questions motivate us to examine the following relationship between the investment (divestment) decision and the productivity of the plants:

$$
\begin{aligned}
\Delta\left(\#{\text { of } \left.\text { Kilns }_{i, m, t}\right)=\beta_{0}+}\right. & \beta_{1} \text { Productivity }_{i, m, t-1} \\
+ & \beta_{2} \text { Productivity }_{i, m, t-1} \cdot \mathbf{1}_{\{t=1985,1986\}} \\
& +\beta_{3} \text { Productivity }_{i, m, t-1} \cdot \mathbf{1}_{\{t=1988,1989,1990\}} \\
& \quad+\text { Controls }_{i, m, t}+\epsilon_{i, m, t},
\end{aligned}
$$

where $\Delta\left(\#\right.$ of Kilns $\left.s_{i, m, t}\right)=\left(\#\right.$ of Kilns $\left._{i, m, t}\right)-\left(\#\right.$ of Kilns $\left._{i, m, t-1}\right)$ and $\left(\#\right.$ of Kilns $\left.s_{i, m, t}\right)$ denotes the number of kilns in plant $i$ in region $m$ in year $t$. We use the number of kilns as a measure of their investment (divestment), believing that the firms' investment (divestment) decisions are better captured by the changes in the number of kilns than by changes in production capacity. This is because the firms probably scrapped one of the kilns in a surviving plant to decrease their capacity in the divestment process. The right- 
hand-side variables reflect the productivity of plant $i$ and interact with the two indicator variables during policy implementations. Naturally, we expect that $\beta_{1}$ is positive, as we believe that the firms invest in plants that are efficient and divest otherwise. If the estimates of $\beta_{2}$ are different from zero, then it means that the divestment decision during policy implementation is different from the base years. In particular, if $\beta_{2}$ is statistically significantly positive, it implies that the firms divested inefficient plants more than they did in the base years. Conversely, if $\beta_{2}$ is statistically significantly negative, it implies that the firms divested inefficient plants less than they did in the base years. The same inference holds for $\beta_{3}$. Due to a discrete nature of the left-hand-side variable, we use ordered logit models to examine how the productivity of a plant affect the firms' choice of how many kilns to scrap in a given plant.

We use three productivity measures. The first one is labor productivity, which is conveniently available in the dataset. The second measure is the utilization rate of plants, which is a proxy of productivity, like investment. ${ }^{10}$ The third measure is total factor productivity, which is widely used in the industrial organization literature. Assuming CobbDouglas production functions, our measure can be recovered as unobserved productivity, $\omega_{i t}$, in the following model:

$$
y_{i t}=\beta_{0}+\beta_{k} k_{i t}+\beta_{l} l_{i t}+\omega_{i t}+\epsilon_{i t},
$$

where (i) $y_{i t}, k_{i t}$, and $l_{i t}$ are logarithms of output, capital input, and labor input for plant $i$ at period $t$, and (ii) $\epsilon_{i t}$ is an idiosyncratic error term. We estimate this model using an approach developed by Olley and Pakes (1996) that relies on dynamic investment in an entry/exit model of firms. Of course, these three measurements have their own limitations and thus developing a new estimation method, which takes into account utilization rate of the firms, would certainly be an interesting direction to pursue. However, it is beyond the scope of this paper and we leave it to future research.

The estimation results are presented in Table 7, whereas the production function results are summarized in Table B1 in Appendix B. Table 7 includes the results for six specifications: the first and fourth columns use labor productivity as the productivity measure, the second and fifth columns use the utilization rate as the productivity measure, and the third and sixth columns use TFP, recovered using the method of Olley and Pakes (1996), as the productivity measure. For all specifications, we add local cement prices

\footnotetext{
${ }^{10}$ For example, Gavazza (2011) also uses the utilization rate as a productivity measure.
} 
Table 7: Divestment Decisions with Three Productivity Measures (Ordered Logit)

\begin{tabular}{|c|c|c|c|c|c|c|}
\hline $\begin{array}{l}\text { Productivity } \\
\text { Measure }\end{array}$ & $\begin{array}{c}\text { (i) } \\
\text { Labor } \\
\text { Productivity }\end{array}$ & $\begin{array}{c}\text { (ii) } \\
\text { Utilization } \\
\text { Rate } \\
\end{array}$ & $\begin{array}{c}\text { (iii) } \\
\text { TFP from } \\
\text { OP (1996) }\end{array}$ & $\begin{array}{c}\text { (iv) } \\
\text { Labor } \\
\text { Productivity }\end{array}$ & $\begin{array}{c}\mathrm{v}) \\
\text { Utilization } \\
\text { Rate }\end{array}$ & $\begin{array}{c}\text { (vi) } \\
\text { TFP from } \\
\text { OP (1996) }\end{array}$ \\
\hline $\begin{array}{l}\text { Productivity } \\
\text { Baseline }\end{array}$ & $\begin{array}{l}.635^{*} \\
(.304)\end{array}$ & $\begin{array}{c}.040^{* * *} \\
(.007)\end{array}$ & $\begin{array}{c}2.365^{* * *} \\
(.402)\end{array}$ & $\begin{array}{l}.432^{*} \\
(.194)\end{array}$ & $\begin{array}{c}.031^{* * *} \\
(.007)\end{array}$ & $\begin{array}{c}1.905^{* * *} \\
(.411)\end{array}$ \\
\hline $\begin{array}{l}\text { Productivity } \\
\times 1985 / 1986\end{array}$ & $\begin{array}{l}-1.269 \\
(1.279)\end{array}$ & $\begin{array}{l}.024 \\
(.022)\end{array}$ & $\begin{array}{l}1.352 \\
(1.455)\end{array}$ & $\begin{array}{r}-1.230 \\
(1.135)\end{array}$ & $\begin{array}{l}.021 \\
(.019)\end{array}$ & $\begin{array}{l}1.174 \\
(1.251)\end{array}$ \\
\hline $\begin{array}{l}\text { Productivity } \\
\times 1988 / 1990\end{array}$ & $\begin{array}{l}.626 \\
(.752)\end{array}$ & $\begin{array}{l}.062^{* *} \\
(.032)\end{array}$ & $\begin{array}{c}5.751^{* *} \\
(2.819)\end{array}$ & $\begin{array}{l}.475 \\
(.691)\end{array}$ & $\begin{array}{l}.047 \\
(.031)\end{array}$ & $\begin{array}{l}4.843^{*} \\
(2.652)\end{array}$ \\
\hline $\begin{array}{l}\Delta \text { Local Cement } \\
\text { Price }\end{array}$ & $\begin{array}{l}7.111 \\
(4.956)\end{array}$ & $\begin{array}{l}3.009 \\
(4.463)\end{array}$ & $\begin{array}{l}4.990 \\
(5.238)\end{array}$ & $\begin{array}{l}6.855 \\
(4.862)\end{array}$ & $\begin{array}{l}2.654 \\
(4.460)\end{array}$ & $\begin{array}{l}4.537 \\
(5.108)\end{array}$ \\
\hline $\begin{array}{l}\text { Fixed Effects } \\
\text { Year } \\
\text { Firm } \\
\text { Area }\end{array}$ & $\begin{array}{l}\sqrt{ } \\
\sqrt{ } \\
\sqrt{ }\end{array}$ & $\begin{array}{l}\sqrt{ } \\
\sqrt{ } \\
\sqrt{ }\end{array}$ & $\begin{array}{l}\sqrt{ } \\
\sqrt{ } \\
\sqrt{ }\end{array}$ & $\sqrt{ }$ & $\sqrt{ }$ & $\sqrt{ }$ \\
\hline $\begin{array}{l}N \\
\text { Adj- }-R^{2}\end{array}$ & $\begin{array}{l}908 \\
.233\end{array}$ & $\begin{array}{l}972 \\
.241\end{array}$ & $\begin{array}{l}908 \\
.266\end{array}$ & $\begin{array}{l}908 \\
.218\end{array}$ & $\begin{array}{l}972 \\
.220\end{array}$ & $\begin{array}{l}908 \\
.248\end{array}$ \\
\hline
\end{tabular}

Note: Significance levels are denoted by $\left.<0.10\left(^{*}\right),<0.05{ }^{* *}\right)$, and $\left.<0.01{ }^{* * *}\right)$. The numbers in parentheses show the standard errors, clustered at the plant-level.

to control for market demand conditions. The first, second, and third columns include fixed effects of year, firm, and area, whereas the fourth to six columns include only year and area fixed effects.

Regardless of the productivity measures, the estimates of baseline productivity $\left(\beta_{1}\right)$ in models (i), (ii), and (iii) are always positive and statistically significant at any level, which implies that the firms invest in more productive plants and divest unproductive plants. This result is consistent with our expectation. On the other hand, the coefficients for productivity interacted with the 1985/1986 $\left(\beta_{2}\right)$, are statistically insignificant for all specifications, which is consistent with the view that the firms did not change their investment/divestment decisions during the first policy intervention. One interesting observation here is that, when we use the utilization rate or TFP as the productivity measures, the coefficients on Productivity interacted with a dummy of 1988/1990 $\left(\beta_{3}\right)$ are positive and statistically significant, which implies that the firms carefully chose unproductive plants to divest even during the second policy intervention. From these results, we conclude that this policy did not distort the firms' scrappage decision rule. The results are robust to different measures of outcome variables, different sample periods, and inclusion of control variables for the technology used in each plant. See Appendix C for a more detailed discussion. 
These results naturally raise an additional question: were those divested plants also inefficient from a social point of view? The results described above imply that inefficient plants within a firm were divested; but not necessarily that inefficient plants from a social point of view were divested. Therefore, to answer this additional question, we drop firm fixed effects from the regression and the results are presented in the fourth to sixth columns in Table 7. As is clear from the results, the previous results still hold qualitatively, which suggests that the divested plants were not only individually inefficient but also socially inefficient. How is this possible? We believe that it is because the plan proposed by MITI was very well crafted. Perhaps, a simple production process, one of the characteristics of this industry, enabled the regulator to easily measure unobserved productivity of the plants and the side-payment scheme helped the firms to agree on the allotment. We discuss this issue further in Section 4.

\subsection{Why did the firms not divest their unused plants?}

We have shown that the policy interventions did not harm consumer welfare nor distort scrappage decision of the firms. However, we have not answered a more fundamental question: why did the firms not divest their unused plants? The fact that firms received little compensation under the side-payment scheme suggests that the economic value of marginal capacity was very low. ${ }^{11}$ However, the divestment took place only very slowly before the policy. There are two possibilities: the firms kept their facility because of (i) strategic interactions and/or (ii) their own merit. In this subsection, as it is extremely difficult to directly quantify the effect of each possibility, we attempt to examine whether these two hypotheses can explain the phenomenon via regression analysis.

\subsubsection{Impact of Excess Capacity on Investment}

The strategic incentive in investment/divestment has been studied mainly in growing industries since the seminal work of Spence (1979), who unravels the preemptive role of investment. ${ }^{12}$ The literature has extended to declining industries, both theoretically and empirically, as demonstrated by Ghemawat and Nalebuff (1990) and Nishiwaki (2016b). Motivated by these theoretical explanations of why firms have an incentive to keep their

\footnotetext{
${ }^{11}$ The average price of clinker was around 14,000 JPY per ton in the early 80's, and firms received only 100 JPY per ton for their divested capacity.

${ }^{12}$ There could be another strategic role of investment-facilitating collusion or reducing quantity produced by other firms. See Appendix E for a more detailed discussion.
} 
production capacity, we empirically examine whether having (excess) capacity affects the investment/divestment behavior of other firms. More specifically, based on the theoretical literature that shows that investing in capacity may deter investment by other firms, we attempt to test whether the firms delay divestment because they expect divestment by other firms. Demonstrating such an effect, however, is difficult because we cannot directly observe firms' expectations. Rather, we employ the following regression model to test our hypothesis:

$$
i_{j, t}=\alpha_{0}+\alpha_{1} \sum_{i \neq j} i_{i, t-1}+\varepsilon_{j, t}, \quad \text { where } i_{j, t}=K_{i, t}-K_{i, t-1} .
$$

If our hypothesis is true, no divestment by other firms in the previous periods leads to divestment in the current period. Or, equivalently, by observing divestment of other firms, firms may decide to keep their production capacity. Therefore, we expect $\alpha_{1}$ to be negative. Note, however, that such specifications in general suffer from the reflection problem as in the social interaction models (e.g., Manski (1993)). ${ }^{13}$ We use the lagged values of (own and other firms') investment as the right-hand-side variables to avoid simultaneity and the reflection problem, which essentially means that we put assumptions on the timing of the investment (divestment) and formation of expectation.

Panel (a) of Table 8 show the estimation results. We run three regressions, including and excluding own investment as a right-hand-side variable. Model (i) uses a whole sample, whereas Model (ii) and (iii) use samples only after 1986, because we worry that the results from Model (i) might be mostly driven by investment or divestment behaviors of the firms caused by policy interventions. Moreover, Model (ii) does not include own investment, whereas Model (iii) does. Including own investment is particularly important because it is well documented that investment is lumpy, and we need to control for it. Moreover, all models include regional-level GDP, and plaster and oil prices, to control for demand and supply conditions. Here, our interest is in the coefficients on other firms' investment, which are negative and statistically significant for all models. This result suggests firms do take into account other firms' investment (divestment) behavior in the previous year when making investment (divestment) decisions this year. In particular, the results mean that the firms divest their capacity less when they observe divestment of other firms. These outcomes are consistent with the hypothesis that firms

\footnotetext{
${ }^{13}$ There are papers that overcome the problem such as Lin (2010), but the existing methods require richer variation in the data to apply in our context.
} 
Table 8: Why did the firms not divest?

\begin{tabular}{|c|c|c|c|}
\hline \multicolumn{4}{|c|}{ Panel (a): Strategic Role of Excess Capacity on Divestment } \\
\hline & Model (i) & Model (ii) & Model (iii) \\
\hline Divestment by other firms & $-.127^{* * *}$ & $-.158^{*}$ & $-.135^{*}$ \\
\hline$\sum_{i \neq j} \log \left(i_{i, t-1}\right)$ & $(.054)$ & $(.079)$ & $(.076)$ \\
\hline Own investment & $-.126^{* * *}$ & & $-.141^{* * *}$ \\
\hline $\log \left(i_{j, t-1}\right)$ & $(.030)$ & & $(.054)$ \\
\hline \multicolumn{4}{|l|}{ Controls } \\
\hline Plant Fixed Effects & $\sqrt{ }$ & $\sqrt{ }$ & $\sqrt{ }$ \\
\hline Year Fixed Effects & $\sqrt{ }$ & $\sqrt{ }$ & $\sqrt{ }$ \\
\hline Some other controls & $\sqrt{ }$ & $\sqrt{ }$ & $\sqrt{ }$ \\
\hline Num. of Obs. & 808 & 426 & 426 \\
\hline Adj- $R^{2}$ & .337 & 175 & 201 \\
\hline \multicolumn{4}{|c|}{ Panel (b): Shape of Marginal Cost Functions } \\
\hline & Model (ii) & Model (iii) & Model (vi) \\
\hline $\log$ (Capacity) & .0126 & .0228 & .0150 \\
\hline & $(.0216)$ & $(.0336)$ & $(.0257)$ \\
\hline $\log$ (Clinker) & -.0234 & $-.0979 * *$ & $-.0697 *$ \\
\hline & $(.0267)$ & $(.0458)$ & $(.0355)$ \\
\hline \multicolumn{4}{|l|}{ Controls } \\
\hline Plant Fixed Effects & $\sqrt{ }$ & $\sqrt{ }$ & $\sqrt{ }$ \\
\hline Year Fixed Effects & $\sqrt{ }$ & $\sqrt{ }$ & $\sqrt{ }$ \\
\hline Num. of Obs. & 972 & 972 & 972 \\
\hline Adj- $R^{2}$ & .940 & .945 & .954 \\
\hline
\end{tabular}

Note: Significance levels are denoted by $<0.10\left(^{*}\right),<0.05\left(^{* *}\right)$, and $<0.01\left(^{(* *}\right)$. The numbers in parentheses show the standard errors, clustered at the plant-level.

delay their own divesting and wait for other firms to divest.

\subsubsection{The Shape of Marginal Cost Functions}

Another possible explanation for excess capacity is that firms keep their capacity by their own merit. If the production exhibits economies of scale in terms of capacity, the seemingly excess part of capacity may contribute to a reduction in costs, and firms may want to hold excess capacity even in the absence of a strategic role. If this is the case, forcing the firms to divest their capacity may harm social welfare. To examine this hypothesis, we regress the estimated marginal cost on capacity, production quantity, productivity measures, and other controls.

$$
\log \left(\mathrm{MC}_{j m t}\right)=\delta_{0}+\delta_{1} \log (\text { Clinker })+\delta_{2} \log (\text { Capacity })+\text { Controls }+\varepsilon_{m t} .
$$

The estimation results are shown in Panel (b) of Table 8. Models (ii), (iii), and (iv) correspond to models in Table 3 in Subsection 3.1. We use these models in Subsection 3.1 
to get the estimated marginal cost. Our focus is on the coefficient of capacity. As for the controls, on top of year- and plant-fixed effects, we include either labor productivity or TFP. We report the estimates when we use labor productivity as the productivity measure. The results are qualitatively similar to the case with TFP. As one can expect, the coefficients on clinker are negative in Models (iii) and (iv), implying that the marginal cost could be lower when the firms produced more, given capacity. However, the interpretation of the sign is not clear. It could be that there are some scale merits in production, or it could be just a result of endogeneity; the firms produce more at the plant with a lower marginal cost. What we want to highlight is the coefficient on capacity. It is not statistically significant in each of the models, which is consistent with the view that capacity has no effect on production cost. Even if economies of scale exist, the scale merit comes from the actual production but not from the capacity. That is, the excess capacity does not contribute to a reduction in cost. Therefore, we conclude that the second hypothesis would not explain the firms' behavior of not divesting their unused plants.

Returning to our original question of "why did the firms not divest their production facility?" our short answer is because of strategic interaction. The cement firms may have played an attrition game by not divesting their production facility while expecting other firms to divest. The government may have noticed this strategic incentive and thus initiated the capacity coordination policy—reducing the firms' capacity simultaneouslywhich eliminates such strategic incentives.

\section{Policy Implications and Caveats}

\subsection{Policy Implications and Generalizability}

Our empirical analysis shows that this series of policy interventions accelerated capital adjustment successfully without increasing firms' market power or distorting their divestment decisions. In principle, the policy helped firms reduce unused production capacity and should not have had any influence on their market power unless the capacity constraint was violated. In this case, it seems that the total reduction was well estimated by the government, and the capacity constraint was held with equality. Therefore, although this capacity coordination policy seems to be anti-competitive, our estimation results do not support this view. Given this assessment, we now discuss policy implications that we can draw from our analysis from the following viewpoints: two key factors 
that led to the success of this policy and generalizabilities.

\subsubsection{Two Key Factors for Successful Implementation}

From our analysis, we would like to highlight two important factors that led to the success of this policy: divestment allotment and total divestment amount. First of all, for effective policy implementation given the total divestment amount, regulators need estimates of the productivity of firms' facilities to decide the allotment of capacity reduction. As is often pointed out in the literature on regulation, however, productivity is typically private information and such asymmetric information between regulators and private companies results in inefficiency. Even with such asymmetric information on the productivity of each plant, regulators could induce private firms to design a mechanism that would efficiently allot divestment. As mentioned in Section 2, under the policy, the private firms in the Japanese cement industry, together with MITI, developed such a mechanism with side payments through negotiations. ${ }^{14}$ Under the side-payment scheme, the marginal profit of the capacity would be equalized across firms, which would help reduce distortion. In our context, asymmetric information may not be a serious problem because the technology of cement production can be evaluated relatively straightforwardly. In particular, during the period of our analysis, technological advancement was modest and the regulator was able to catch up with firms in terms of understanding and evaluating existing technology. Furthermore, detailed micro data on production were available to obtain precise estimates of productivity. These factors enabled the regulator to assess the facilities accurately.

Second and more importantly, determining how much capacity should be scrapped in the industry as a whole is a challenging task. This is more difficult than determining the allotment given the total divestment amount because the firms have an incentive to overstate the required divestment amount. In oligopolistic competition, all firms interests are aligned in a sense that they all benefit from reducing the total production. Therefore, building a mechanism to aggregate firms' private information to determine the total divestment amount is fundamentally more difficult to determine the allotment. From the social welfare point of view, it is extremely important that the policy maker correctly assesses the needs for divestment amount. In our context, again, the simplicity of production technology helped the policy maker in this regard as well.

\footnotetext{
${ }^{14}$ This fact may raise endogeneity concerns, which are discussed in the following section.
} 
Also, even if the policy maker were able to assess the needs for divestment in a given moment of time, the demand and supply environment would change over time. This issue raises another informational problem: the government may not be able to predict future demand accurately, whereas firms in the industry have better information about demand and supply. If regulators can predict future demand with high accuracy, they can correctly measure excess capacity. In practice, however, this may not be realistic. In fact, right after the second policy intervention, the Japanese economy faced a boom called the "Heisei bubble" or the "Japanese asset price bubble" between December 1986 and February 1991, and cement demand recovered during this period, as shown in Panel (a) of Figure $1 .{ }^{15}$ Even though net exports were consistently positive, the cement industry needed to decrease exports and increase imports during this period to meet domestic demand. Although this event might be irregular in declining industries, it is important that policymakers keep such possibilities in mind when developing policy.

\subsubsection{Generalizabilities of Capacity Coordination}

Would a similar policy be applicable to other industries that currently face excess capacity issues? Here, the existence of a coordination/commitment device is the fundamental condition for such a policy to be applicable. An ideal environment to apply capacity coordination policy would be an industry that (a) governments can initiate and monitor capacity coordination and (b) goods are mostly supplied and consumed domestically, as in the Japanese cement industry. On the other hand, implementing capacity coordination policy might be challenging for some industries, such as the shipbuilding industry and the steel industry, if the major players are scattered across multiple countries. In such a case, an international agreement would be necessary, which is practically difficult to reach, because firms' incentives are quite heterogeneous across different countries and political considerations may not be aligned with economic efficiency. In fact, OECD has been intensively discussing the overcapacity issues on the shipbuilding and steel industries but making an enforceable agreement has been difficult. Initiatives by international organizations would be important for capacity coordination to solve global excess capacity issues.

\footnotetext{
${ }^{15}$ Though the Heisei period started in January 1989, the Heisei bubble began in December 1986 because of a gap in recognition.
} 


\subsection{Caveats}

In the previous subsection, we conclude that the capacity coordination policy applied to the Japanese cement industry successfully reduced excess capacity without hurting consumer welfare and caused scrapping excessive plants in order of productivity. Also, we draw general implications on the applicability of such capacity coordination. Do these results immediately support the application of this policy to other industries? This subsection provides discussion on the caveats regarding the capacity coordination policy for possible generalization.

Endogeneity concerns The government's involvement in the negotiation process might raise two potential endogeneity concerns: endogeneity of allotment and endogeneity of the policy itself. As for the former type of concern, we are not interested in the outcomes when allotment is randomly assigned to each firm, but we are interested in evaluating the policy from the viewpoints of consumers and producers when it is well designed by the regulator. In this regard, our results should not be affected by such an endogeneity concern. Of course, how to allocate divestment allotment itself is an important question and, as mentioned earlier, designing a mechanism would be of interest, in particular from a theoretical point of view. However, it is beyond the scope of this paper and left to future research. As for the latter type of concern, we must admit that our results cannot be applied to all industries. We are not claiming that this policy is universally effective, and it should be obvious that applying this policy to a growing industry does not make sense. In other words, we are interested in measuring the effects of this policy when applied to a declining industry or an industry in recession where there is a need for capacity reduction, rather than the effects of this policy when it is exogenously applied to a randomly chosen industry. Therefore, we believe that the results presented in this paper would not be affected by such endogeneity concerns.

Dynamic consequences As pointed out by Kamita (2010), capacity coordination may induce collusion over time. In this regard, we do not find evidence of such anticompetitive behavior in the Japanese cement industry after policy implementation, whereas the Aloha-Hawaii case promoted cooperation for several years until new entrants joined the market. It is therefore important to monitor the industry even after policy implementation. Another dynamic consequence that our analysis cannot capture is whether this 
policy prolonged the life of inefficient firms. Thanks to this policy intervention, some inefficient firms did survive through the low demand periods. Without this policy intervention, some inefficient firms would have been forced to exit the market. In Subsection 3.2 , we find that the divested plants are socially inefficient, and the firms' divestment decisions are not distorted by the policy, which suggests that the firms' exit decisions are also not distorted. However, we do not model or estimate exit decisions explicitly.

\section{Conclusion}

Excess production capacity has been a major concern in many countries, particularly when an industry faces declining demand. Strategic interaction among firms may delay efficient scrappages of production capacity and policy interventions that eliminate such strategic incentives may improve efficiency. Using plant-level data on the Japanese cement industry, this paper empirically studies the effectiveness of a capacity coordination policy that forces the firms to simultaneously reduce their production capacity.

Our estimation results show that a capacity coordination policy can effectively reduce excess capacity without increasing their market power or distorting firms' scrappage decisions. Although this series of policy interventions seems to be successful, some caveats apply in relation to capacity coordination policy in other industries/countries: (i) estimation of excess capacity and its allotment, and (ii) dynamic effects and consequences of the policy intervention. Thus, policymakers with an interest in introducing capacity coordination policy must keep these caveats in mind.

\section{References}

Aghion, Philippe, Jing Cai, Mathias Dewatripont, Luosha Du, Ann Harrison, and Patrick Legros, "Industrial Policy and Competition," American Economic Journal: Macroeconomics, October 2015, 7 (4), 1-32.

Aguirregabiria, Victor and Margaret Slade, "Empirical Models of Firms and Industries," Canadian Journal of Economics, 2017, 50 (5), 1445-1488.

Aiginger, Karl and Dani Rodrik, "Rebirth of Industrial Policy and an Agenda for the Twenty-First Century," Journal of Industry, Competition and Trade, 2020, 20, 189-207.

Bain, Joe S., Barriers to New Competition, Cambrige, MA: Harvard University Press, 1962. 
Berry, Steven, James Levinsohn, and Ariel Pakes, "Automobile Prices in Market Equilibrium," Econometrica, 1995, 63 (4), 841-890.

Blair, Roger D., James Mak, and Carl Bonham, "Collusive Duopoly: The Economic Effects of the Aloha and Hawaiian Airlines' Agreement to Reduce Capacity," Antitrust Law Journal, 2007, 74 (2), 409-438.

Bresnahan, Timothy F., “The Oligopoly Solution Concept Is Identified," Economics Letters, 1982, 10 (1-2), 87-92.

Das, Sanghamitra, "A Micro-Econometric Model of Capital Utilization and Retirement: The Case of the U.S. Cement Industry," Review of Economic Studies, 1992, 59 (2), 277297.

De Loecker, Jan, Pinelopi K. Goldberg, Amit K. Khandelwal, and Nina Pavcnik, "Prices, Markups, and Trade Reform," Econometrica, 2016, 84 (2), 445-510.

Deily, Mary E., "Exit Strategies and Plant-Closing Decisions: The Case of Steel," RAND Journal of Economics, 1991, 22 (2), 250-263.

Devidson, Carl and Raymond Deneckere, "Excess Capacity and Collusion," International Economic Review, 1990, 31 (3), 521-541.

Fudenberg, Drew and Jean Tirole, "A Theory of Exit in Duopoly," Econometrica, 1986, 54 (4), 943-960.

Gavazza, Alessandro, "The Role of Trading Frictions in Real Asset Markets," American Economic Review, 2011, 101 (4), 1106-1143.

Ghemawat, Pankaj and Barry Nalebuff, “Exit,” RAND Journal of Economics, 1985, 16 (2), 184-194.

_ and _, "The Devolution of Declining Industries," Quarterly Journal of Economics, 1990, 105 (1), 167-186.

Hampton, Kyle and Katerina Sherstyuk, "Demand Shocks, Capacity Coordination, and Industry Performance: Lessons from an Economic Laboratory," RAND Journal of Economics, 2012, 43 (1), 139-166.

Japan Cement Association, ed., 50-Year History of the Japan Cement Association (Cement Kyōkai 50-nen no Ayumi), Tokyo: Japan Cement Association, 1998.

Kalouptsidi, Myrto, Panle Jia Barwick, and Nahim Zahur, "China's Industrial Policy: An Empirical Investigation,” NBER Working Paper 26075, 2020.

Kamita, Rene Y., "Analyzing the Effects of Temporary Antitrust Immunity: The AlohaHawaiian Immunity Agreement," Journal of Law and Economics, 2010, 53 (2), 239-261.

Kreps, David M. and Jose A. Scheinkman, "Quantity Precommitment and Bertrand Competition Yield Cournot Outcomes," Bell Journal of Economics, 1983, 14 (2), 326337. 
Lau, Lawrence J., "On Identifying the Degree of Competitiveness from Industry Price and Output Data," Economics Letters, 1982, 10 (1-2), 93-99.

Lee, Yoonseok, Andrey Stoyanov, and Nikolay Zubanov, "Olley and Pakes-style Production Function Estimators with Firm Fixed Effects," Oxford Bulletin of Economics and Statistics, 2019, 81, 79-97.

Levinsohn, James and Amil Petrin, "Estimating Production Functions Using Inputs to Control for Unobserbables," Review of Economic Studies, 2003, 70, 317-341.

Lieberman, Marvin B., "Exit from Declining Industries: 'Shakeout' or 'Stakeout'," RAND Journal of Economics, 1990, 21 (4), 538-554.

Lin, Xu, "Identifying Peer Effects in Student Academic Achievement by Spatial Autoregressive Models with Group Unobservables," Journal of Labor Economics, 2010, 28 (4), 825-860.

Manski, Charles F., "Identification of Endogenous Social Effects: The Reflection Problem," The Review of Economic Studies, 1993, 60 (3), 531-542.

Miller, Nathan H. and Matthew Osborne, "Spatial differentiation and price discrimination in the cement industry: evidence from a structural model," RAND Journal of Economics, 2014, 45 (2), 221-247.

Nishiwaki, Masato, "Does Vertical Integration Facilitate Upstream Collusion? An Empirical Study,” 2016. mimeo.

_ , "Horizontal Mergers and Divestment Dynamics in a Sunset Industry," RAND Journal of Economics, 2016, 47 (4), 961-997.

_ and Hyoeg Ug Kwon, "Are Losers Picked? An Empirical Analysis of Capacity Divestment and Production Reallocation in the Japanese Cement Industry," Journal of Industrial Economics, 2013, 61 (2), 430-467.

Olley, Steven G. and Ariel Pakes, "The Dynamics of Productivity in the Telecommunications Equipment Industry,” Econometrica, 1996, 64(6), 1263-1297.

Röller, Lars-Hendrik and Frode Steen, "On the Workings of a Cartel: Evidence from the Norwegian Cement Industry,” American Economic Review, 2006, 96 (1), 321-338.

Ryan, Stephen P., "The Costs of Environmental Regulation in a Concentrated Industry," Econometrica, 2012, 80 (3), 1019-1061.

Salvo, Alberto, "Inferring market power under the threat of entry: the case of the Brazilian cement industry," RAND Journal of Economics, 2010, 41 (2), 326-350.

Shcherbakov, Oleksandr and Naoki Wakamori, "Identifying the Degree of Collusion Under Proportional Reduction," Bank of Canada Staff Working Papers 17-51, 2017. 
Shimoda, Takashi, "History of Cement Manufacturing Technology," in Center of the History of Japanese Industrial Technology, ed., Survey Reports on the Systemization of Technologies, Vol. 23, Tokyo: National Museum of Nature and Science, 2016, pp. 1-114.

Smith, John Maynard, "The Theory of Games and the Evolution of Animal Conflicts," Journal of Theoretical Biology, 1974, 47 (1), 209-221.

Spence, A. Michael, "Entry, Capacity, Investment and Oligopolistic Pricing," Bell Journal of Economics, 1977, 8 (2), 534-544.

_ , "Investment Strategy and Growth in a New Market," Bell Journal of Economics, 1979, $10(1), 1-19$.

Steen, Frode and Kjell G. Salvanes, "Testing for Market Power Using a Dynamic Oligopoly Model," International Journal of Industrial Organization, 1999, 17, 147-177.

Takahashi, Yuya, "Estimating a War of Attrition: The Case of the US Movie Theater Industry," American Economic Review, 2015, 105 (7), 2204-2241.

Wada, Masatake, "Ceramic and Building Material Industries (Yōgyō Kenzai Sangyō)," in The Society for Industrial Studies, ed., History of Industries in Postwar Japan (Sengo Nihon Sangyō-shi), Tokyo:Tōyō Keizai Shinpō-sha, 1995, pp. 203-219.

Wenders, John T., "Excess Capacity as a Barrier to Entry," Journal of Industrial Economics, 1971, 20 (1), 14-19.

Whinston, Michael D., "Exit with Multiplant Firms," RAND Journal of Economics, 1988, 19 (4), 568-588. 


\section{Appendix A Additional Tables}

Table Al below summarizes the historical events related to the capacity coordination policies, whereas Table A2 shows the estimation results when we regress the regional cement prices on the dummy variables that indicate the periods of policy implementation.

Table Al: A Chronological Table

\begin{tabular}{ll}
\hline \hline 1970 & Data begin \\
1973 & Demand shock 1: The first oil crisis \\
$1975.11-1976.1$ & Recession cartel was allowed in the cement industry \\
$1977.6-1977.12$ & Recession cartel was allowed in the cement industry \\
1979 & Demand shock 2: The second oil crisis \\
$1983.8-1983.12$ & Recession cartel was allowed in the cement industry \\
$1985.1-1986.3$ & $\begin{array}{l}\text { Capacity coordination 1: Government allowed cartel to reduce } \\
\text { capacity by 30 out of 129 million tons (of which only 5 were in use) }\end{array}$ \\
1985.09 & Demand shock 3: Yen appreciation due to Plaza agreement \\
$1986.01-1991.02$ & Demand shock 4: Heisei bubble started \\
$1988.12-1991.03$ & $\begin{array}{l}\text { Capacity coordination 2: Government allowed cartel to reduce } \\
\text { capacity by 10.7 out of 98 million tons (of which all 10.7 were in use) }\end{array}$ \\
1995 & Data end \\
\hline
\end{tabular}

Table A2: Effects of the Policy on Raw Prices

\begin{tabular}{lcccccc}
\hline & (i) & (ii) & (iii) & (iv) & (v) & (vi) \\
Dependent Variable & $\ln \left(P_{m t}\right)$ & $\ln \left(P_{m t}\right)$ & $\ln \left(P_{m t}\right)$ & $\ln \left(P_{m t}\right)$ & $\ln \left(P_{m t}\right)$ & $\ln \left(P_{m t}\right)$ \\
\hline \hline $1985 / 1986$ Dummy & .00556 & .015 & .00676 & $-.0151^{*}$ & -.00782 & -.0056 \\
& $(.0072)$ & $(.0084)$ & $(.0068)$ & $(.0066)$ & $(.0081)$ & $(.0079)$ \\
$1988 / 1990$ Dummy & $-.0396^{*}$ & -.0237 & -.0116 & $-.0480^{*}$ & -.0218 & $-.0264^{*}$ \\
& $(.0194)$ & $(.0153)$ & $(.0125)$ & $(.0204)$ & $(.0151)$ & $(.0124)$ \\
Year Spline & $2 \mathrm{nd}$ & $3 \mathrm{rd}$ & $4 \mathrm{th}$ & $2 \mathrm{nd}$ & 3rd & 4 th \\
Other controls & & & & $\mathrm{X}$ & $\mathrm{X}$ & $\mathrm{X}$ \\
Area Fixed Effects & $\mathrm{X}$ & $\mathrm{X}$ & $\mathrm{X}$ & $\mathrm{X}$ & $\mathrm{X}$ & $\mathrm{X}$ \\
\hline $\mathrm{N}$ & 184 & 184 & 184 & 176 & 176 & 176 \\
Adj-R & .903 & .907 & .908 & .913 & .919 & .918 \\
\hline
\end{tabular}

Note: Significance levels are denoted by $<0.10\left({ }^{*}\right),<0.05\left({ }^{* *}\right)$, and $<0.01\left({ }^{* * *}\right)$. The numbers in parentheses show the standard errors, which are clustered at the area. "Year Spline" indicates the order of polynomials that we include for each specification. "Other Controls" include regional-level real GDP, real wage, and prices of limestone and plaster. We have smaller observations for Models (iv), (v), and (vi), as we do not have plaster prices for one of the years. 


\section{Appendix B Production Function Estimation}

Table B1 presents the estimation results of the production function estimation. The point estimates suggest that the technology exhibits increasing returns to scale, but, statistically, we cannot reject the hypothesis that the technology is constant returns to scale. Since the cement industry is a heavy industry with a huge upfront investment, it is not so surprising that the estimated scale parameter is high. In the literature, other papers including Levinsohn and Petrin (2003), De Loecker, Goldberg, Khandelwal and Pavcnik (2016) and Lee, Stoyanov and Zubanov (2019) also report point estimates that exhibit increasing returns to scale in some industries.

Table B1: Production Function Estimation

\begin{tabular}{lcc}
\hline & FE & OP \\
\hline \hline Capital & $.808^{* * *}$ & $.941^{* * *}$ \\
& $(.091)$ & $(.112)$ \\
Labor & $.307^{* * *}$ & $.160^{* * *}$ \\
& $(.099)$ & $(.056)$ \\
Firm Fixed Effects & $\sqrt{ }$ & \\
Controlling for Year & $\sqrt{ }$ & $\sqrt{ }$ \\
\hline Num. of Observations & 1,130 & 1,124 \\
\hline
\end{tabular}

Note: Significance levels are denoted by $<0.10\left(^{*}\right),<0.05$ $\left({ }^{* *}\right)$, and $\left.<0.01{ }^{* * *}\right)$. The numbers in parentheses show the standard errors, clustered at the plant-level. 


\section{Appendix C Robustness of Divestment Decisions}

Robustness Check: A Continuous measure In our main analysis, we use the change in the number of kilns as a measure of investment (divestment), which is a discrete variable, and, to cope with this discreteness of the outcome variable, we use a series of ordered logit models. To check the robustness of our results, we now use capacity, which is more or less a continuous measure, as a proxy of investment (divestment) and estimate the following model:

$$
\begin{aligned}
\text { Capacity }_{i, m, t}-\text { Capacity }_{i, m, t-1}=\beta_{0}+ & \beta_{1} \text { Productivity }_{i, m, t-1} \\
+ & \beta_{2} \text { Productivity }_{i, m, t-1} \cdot \mathbf{1}_{\{t=1985,1986\}} \\
+ & \beta_{3} \text { Productivity }_{i, m, t-1} \cdot \mathbf{1}_{\{t=1988,1989,1990\}} \\
& + \text { Controls }_{i, m, t}+\epsilon_{i, m, t} .
\end{aligned}
$$

The left-hand-side variable is positive (negative) if the firm invests (divests) and the righthand-side variables are the same as in Equation (4), except for the error term. This is because, as this lag specification may call for a concern on autocorrelation, we address this concern by introducing AR(1) structure on the error term, i.e., $\epsilon_{i, m, t}=\rho \epsilon_{i, m, t-1}+\eta_{i, m, t}$.

The estimation results are summarized in Table $\mathrm{Cl}$. We have exactly the same specifications as in Table 7; we run a series of regression models with the firm fixed effects to examine whether the firms divested inefficient plants within a firm in the first three columns, whereas we do the same exercise but drop the firm fixed effects to examine whether the divested plants were also inefficient from a social point of view in the last three columns. The results presented here support our previous conclusions; basically the firms invest in productive plants and divest unproductive plants from the viewpoints of both the individual firm and social welfare, and their decision rule was not affected by the policy interventions.

Robustness Check: Sample period and technology Another potential concern for our analysis could be that the results are mainly driven by the building phase in the 1970s rather than by the scrappage phase in the 1980s. To address this concern, we first estimate the main model, which uses the change in capacity as a left-hand-side variable, limiting our samples to the observations between 1980 and 1995. Most of the construction of NSP kilns took place in the 1970s, so excluding the samples prior to 1980 enables 
Table C1: Divestment Decisions with Three Productivity Measures (FE)

\begin{tabular}{|c|c|c|c|c|c|c|}
\hline & (i) & (ii) & (iii) & (iv) & (v) & (vi) \\
\hline Productivity & Labor & Utilization & TFP from & Labor & Utilization & TFP from \\
\hline Measure & Productivity & Rate & OP (1996) & Productivity & Rate & OP (1996) \\
\hline Productivity & .013 & $.002^{* * *}$ & $.123^{* * *}$ & $.011^{*}$ & $.002^{* * *}$ & $.118^{* * *}$ \\
\hline Baseline & $(.008)$ & $(.000)$ & $(.015)$ & $(.007)$ & $(.000)$ & $(.013)$ \\
\hline Productivity & -.002 & -.000 & .000 & -.002 & -.000 & .001 \\
\hline$\times 1985 / 1986$ & $(.002)$ & $(.000)$ & $(.000)$ & $(.002)$ & $(.000)$ & $(.001)$ \\
\hline Productivity & -.002 & -.000 & -.000 & .002 & -.001 & -.000 \\
\hline$\times 1988 / 1990$ & $(.002)$ & $(.000)$ & $(.001)$ & $(.002)$ & $(.000)$ & $(.001)$ \\
\hline$\Delta$ Local Cement & $.326^{* * *}$ & $.278^{* * *}$ & $.233^{* * *}$ & $0.305^{* * *}$ & $0.268^{* * *}$ & $0.215^{* * *}$ \\
\hline Price & $(.066)$ & $(.066)$ & (.063) & $(.064)$ & $(.065)$ & $(.061)$ \\
\hline \multicolumn{7}{|l|}{ Fixed Effects } \\
\hline Year & $\sqrt{ }$ & $\sqrt{ }$ & $\sqrt{ }$ & $\sqrt{ }$ & $\sqrt{ }$ & $\sqrt{ }$ \\
\hline Firm & $\sqrt{ }$ & $\sqrt{ }$ & $\sqrt{ }$ & & & \\
\hline Area & $\sqrt{ }$ & $\sqrt{ }$ & $\sqrt{ }$ & $\sqrt{ }$ & $\sqrt{ }$ & $\sqrt{ }$ \\
\hline$N$ & 908 & 972 & 908 & 908 & 972 & 908 \\
\hline
\end{tabular}

Note: Significance levels are denoted by $<0.1\left(^{(*)}\right),<0.05\left(^{* *}\right)$, and $<0.01\left(^{* * *}\right)$. The numbers in parentheses show the standard errors, clustered at the plant-level.

us to exclusively focus on the divestment. The results are demonstrated in the first three columns in Table C2. To further ease concerns, we even more explicitly control this by focusing on the samples with a negative difference in capacity. Moreover, when doing so, we also control for the technological aspect of the plant by including the fraction of new types of kilns. The fraction of new kilns is defined as the number of SP and NSP kilns over the total number of kilns in a plant. As explained in Section 2, SP and NSP kilns are relatively new technology that became dominant in the 1970s and 1980s. Therefore, inclusion of this variable enables us to control for the heterogeneity in firms' technology across plants. These estimation results are in the last three columns in Table C2.

The results are not different from the previous specifications. We can again confirm that the firms divested unproductive plants within the firm. ${ }^{16}$ For the first three specifications, the results are not only qualitatively, but also quantitatively very similar, implying that the results are not driven by the building-up phase but rather by the divestment phase. Also, the last three specifications demonstrate that even controlling for the technology, the coefficients on productivity $\left(\beta_{1}\right)$ are still positive and statistically significant,

\footnotetext{
${ }^{16}$ We also check the robustness of our results by dropping the firm fixed effects, and confirm that the results are not changed.
} 
Table C2: Divestment Decisions (Technology Controlled)

\begin{tabular}{|c|c|c|c|c|c|c|}
\hline $\begin{array}{l}\text { Productivity } \\
\text { Measure }\end{array}$ & $\begin{array}{c}\text { (i) } \\
\text { Labor } \\
\text { Productivity }\end{array}$ & $\begin{array}{c}\text { (ii) } \\
\text { Utilization } \\
\text { Rate }\end{array}$ & $\begin{array}{c}\text { (iii) } \\
\text { TFP from } \\
\text { OP (1996) }\end{array}$ & $\begin{array}{c}\text { (iv) } \\
\text { Labor } \\
\text { Productivity }\end{array}$ & $\begin{array}{c}\text { (v) } \\
\text { Utilization } \\
\text { Rate }\end{array}$ & $\begin{array}{c}\text { (vi) } \\
\text { TFP from } \\
\text { OP (1996) }\end{array}$ \\
\hline Productivity & $.031^{* *}$ & $.002^{* * *}$ & $.125^{* * *}$ & $.111^{* *}$ & $.006^{* *}$ & $.299 * *$ \\
\hline Baseline & $(.013)$ & $(.000)$ & $(.021)$ & $(.043)$ & $(.002)$ & $(.108)$ \\
\hline $\begin{array}{l}\text { Productivity } \\
\times 1985 / 1986\end{array}$ & $\begin{array}{l}-.035 \\
(.021)\end{array}$ & $\begin{array}{l}-.000 \\
(.001)\end{array}$ & $\begin{array}{l}-.030 \\
(.062)\end{array}$ & $\begin{array}{l}-.035 \\
(.167)\end{array}$ & $\begin{array}{l}.002 \\
(.005)\end{array}$ & $\begin{array}{l}0.187 \\
(.253)\end{array}$ \\
\hline $\begin{array}{l}\text { Productivity } \\
\times 1988 / 1990\end{array}$ & $\begin{array}{l}-.020 \\
(.013)\end{array}$ & $\begin{array}{l}-.000 \\
(.001)\end{array}$ & $\begin{array}{l}-.013 \\
(.098)\end{array}$ & $\begin{array}{l}-.004 \\
(.011)\end{array}$ & $\begin{array}{l}.001 \\
(.001)\end{array}$ & $\begin{array}{l}-.006 \\
(.005)\end{array}$ \\
\hline Fraction of New Kilns & & & & $\begin{array}{l}-.143 \\
(.112)\end{array}$ & $\begin{array}{l}-.082 \\
(.106)\end{array}$ & $\begin{array}{l}-.092 \\
(.103)\end{array}$ \\
\hline Num. of Kilns & & & & $\begin{array}{c}-.034^{*} \\
(.031)\end{array}$ & $\begin{array}{l}-.015 \\
(.024)\end{array}$ & $\begin{array}{l}-.019 \\
(.025)\end{array}$ \\
\hline $\begin{array}{l}\Delta \text { Local Cement } \\
\text { Price }\end{array}$ & $\begin{array}{l}.292 \\
(.115)\end{array}$ & $\begin{array}{l}.211 \\
(.118)\end{array}$ & $\begin{array}{l}.222 \\
(.118)\end{array}$ & $\begin{array}{l}.990 \\
(.804)\end{array}$ & $\begin{array}{l}.793 \\
(.757)\end{array}$ & $\begin{array}{l}.903 \\
(.808)\end{array}$ \\
\hline $\begin{array}{l}\text { Fixed Effects } \\
\text { Year } \\
\text { Firm } \\
\text { Area } \\
\end{array}$ & $\begin{array}{l}\sqrt{ } \\
\sqrt{ } \\
\sqrt{ }\end{array}$ & $\begin{array}{l}\sqrt{ } \\
\sqrt{ } \\
\sqrt{ }\end{array}$ & $\begin{array}{l}\sqrt{ } \\
\sqrt{ } \\
\sqrt{ }\end{array}$ & $\begin{array}{l}\sqrt{ } \\
\sqrt{ } \\
\sqrt{ }\end{array}$ & $\begin{array}{l}\sqrt{ } \\
\sqrt{ } \\
\sqrt{ }\end{array}$ & $\begin{array}{l}\sqrt{ } \\
\sqrt{ } \\
\sqrt{ }\end{array}$ \\
\hline $\begin{array}{l}N \\
\text { Pseudo- } R^{2}\end{array}$ & $\begin{array}{l}617 \\
.283\end{array}$ & $\begin{array}{l}622 \\
.332\end{array}$ & $\begin{array}{l}617 \\
.332\end{array}$ & $\begin{array}{l}111 \\
.255\end{array}$ & $\begin{array}{l}111 \\
.445\end{array}$ & $\begin{array}{l}111 \\
.419\end{array}$ \\
\hline
\end{tabular}

Note: Significance levels are denoted by $<0.10\left(^{*}\right),<0.05\left({ }^{* *}\right)$, and $<0.01\left({ }^{* *}\right)$. The numbers in parentheses show the standard errors, clustered at the plant-level.

whereas the fraction of new kilns is not. This result could indicate that productivity is a better measure than the fraction of new kilns, which would justify the usage of productivity when implementing capacity coordination policy. 


\section{Appendix D Estimating Conduct Parameters}

As discussed in Section 3, we estimate a model that allows for more flexible modes of competition. In the literature of conduct parameter estimation, outcomes are summarized by a conduct parameter $\theta$, and the firm's first-order condition is expressed as

$$
P_{m t}=\frac{\partial c\left(q_{f m t}\right)}{\partial q_{f m t}}-\theta q_{f m t} \frac{P\left(Q_{m t}\right)}{Q_{m t}} .
$$

This formulation nests perfect competition, $\theta=0$, Cournot competition, $\theta=1, N$ firm symmetric perfect collusion, $\theta=N$, etc. See Aguirregabiria and Slade (2017) for more detail derivation and interpretation of this formulation. Using this model, we can calculate the markups as

$$
\operatorname{Markup}_{j m t}=\frac{\theta}{\eta_{j m t}},
$$

where $\eta_{j m t}$ is the demand elasticity firm $j$ faces in market $m$ in year $t$. To identify the conduct parameter, we change the demand function and include a parameter so that the elasticity is no longer constant. Formally, we specify the demand function as follows:

$$
\log \left(Q_{m t}\right)=\left(\alpha_{1}+\alpha_{2} \log (\text { Oil Price })\right) \log \left(P_{m t}\right)+X_{m t} \beta+\varepsilon_{m t},
$$

where all notation and variable definition follow Equation 1 except that we additionally include the logarithm of (real) oil price that affects demand elasticity. The demand estimation follows the same steps and empirical strategy as in Section 3.

Table D1 present the estimation results. The estimated conduct parameter ranges from 1.6 to around 0 , which suggests that the conduct parameter estimation is not very robust to specification of the demand system. However, our focus is to see whether the markups changed during the policy period. In this regard, all three specifications present the same results; the markup did not increase during the policy period. 


\section{Table D1: Conduct Parameters and Markup Regression Results}

\begin{tabular}{|c|c|c|c|}
\hline \multicolumn{4}{|c|}{ Panel (a): Estimated Conduct Parameters } \\
\hline & Model (ii) & Model (iii) & Model (vi) \\
\hline \multirow[t]{2}{*}{ Estimated Conduct Parameter } & $1.665^{*}$ & $.151^{*}$ & -.001 \\
\hline & $(.859)$ & (.078) & $(.007)$ \\
\hline \multicolumn{4}{|c|}{ Panel (b): Markup Regression Results } \\
\hline & Model (ii) & Model (iii) & Model (vi) \\
\hline \multirow[t]{2}{*}{ 1985/1986 Dummy } & .000 & .000 & $-.000^{* * *}$ \\
\hline & $(.000)$ & $(.000)$ & $(.000)$ \\
\hline \multirow[t]{2}{*}{ 1988/1990 Dummy } & .000 & .000 & .000 \\
\hline & $(.000)$ & $(.000)$ & $(.000)$ \\
\hline Year up to 4 th & $\sqrt{ }$ & $\sqrt{ }$ & $\sqrt{ }$ \\
\hline Firm Fixed Effects & $\sqrt{ }$ & $\sqrt{ }$ & $\sqrt{ }$ \\
\hline Area Fixed Effects & $\sqrt{ }$ & $\sqrt{ }$ & $\sqrt{ }$ \\
\hline Num. of Obs. & 793 & 793 & 793 \\
\hline $\operatorname{Adj~} R^{2}$ & 0.640 & 0.640 & 0.261 \\
\hline
\end{tabular}

Note: Panel (a) shows the estimated conduct parameters for three different specifications, corresponding to models (ii), (iii) and (iv) in Table 3. Panel (b) shows the results for the following regression:

$$
\text { Markup }_{m t}=\gamma_{0}+\gamma_{1} \mathbf{1}_{\{t=1985,1986\}}+\gamma_{2} \mathbf{1}_{\{t=1988,1989,1990\}}+\text { Controls }+\varepsilon_{m t} .
$$

Significance levels are denoted by $<0.10\left({ }^{*}\right),<0.05\left(^{* *}\right)$, and $<0.01\left(^{* * *}\right)$. The numbers in parentheses show the standard errors, clustered at the firm level. 


\section{Appendix E Why did not the Firms Divest?}

As shown in Section 2, the firms did not divest their production capacity even though demand for cement was much lower than the industry's total capacity. A natural question then arises: "Why did the firms not divest their production facility?" In answering this question, we first investigate the firms' behavior theoretically to determine the possible impacts of holding (excess) capacity. Consider a dynamic oligopoly model, similar to Nishiwaki (2016b), with both static and dynamic decisions. Static decisions include choices regarding quantity, whereas dynamic decisions include investment/divestment and entry/exit. This framework enables us to determine whether excess capacity could potentially affect other firms through three distinct channels. Excess capacity may affect (1) quantity produced by rival firms, (2) investment or divestment of rival firms, and (3) entry or exit of rival firms. The last channel is addressed in two different bodies of literature: strategic entry deterrence as in Wenders (1971) and Spence (1977), and exit games as in Fudenberg and Tirole (1986), Smith (1974), Ghemawat and Nalebuff (1985), and Takahashi (2015). In our case, however, there were few entries or exits observed in the data, which does not allow us to study such effects quantitatively. Therefore, in the following analysis, we focus on the first and second channels which are closely related to each other.

The first channel examines the effect of investment, a dynamic decision, on the quantity produced, a static decision. Naturally, firms cannot produce more than their capacity and thus, quantity is affected by capacity choices as in Kreps and Scheinkman (1983). Moreover, if production cost depends on production capacity (e.g., economies of scale), firms may invest more to reduce their own production costs, which results in a change in the production quantities of their rivals. Even though capacity has no direct impact on production costs, however, unused capacity may still affect other firms' production quantities in a repeated game. As pointed out by Devidson and Deneckere (1990), by holding excess capacity, it is easier to sustain collusion because excess capacity makes the punishment harsher. The possibility of economies of scale and the second channel are examined in Section 3.

Impact of excess capacity on quantity produced Here, we empirically investigate the first channel, i.e., whether having (excess) capacity affects production. To do so, consider 
the following static maximization problem of firm $j$ :

$$
\max _{q_{j}} P\left(q_{j}, q_{-j}\right) q_{j}-c_{j}\left(q_{j}\right) \text { s.t. } q_{j} \leq K_{j},
$$

where $q_{j}$ and $q_{-j}$ are the output of firm $j$ and all other firms, respectively, $c_{j}(\cdot)$ is a cost function for firm $j$, and $K_{j}$ is the maximum capacity that firm $j$ can produce. When solving for an equilibrium, the equilibrium quantity for firm $j$ is expressed as:

$$
q_{j}^{*}=Q_{j}^{*}\left(K_{j}, K_{-j}\right)
$$

which means that the equilibrium quantity is a function of capacities. ${ }^{17}$ Therefore, we first estimate this relationship using the following specification:

$$
\text { [Specification 1] } \quad q_{j, t}=\alpha_{0}+\alpha_{1} K_{j, t}+\alpha_{2} \sum_{i \neq j} K_{i, t}+\varepsilon_{j, t} .
$$

Here the parameter of interest is $\alpha_{2}$, which quantifies the impact of rivals' capacity on the quantity produced. Although Specification 1 is derived from a theoretical model and $\alpha_{2}$ reveals whether or not having capacity itself affects the production of other firms, we still cannot determine whether having excess capacity affects production. To see the impact of excess capacity on quantity produced, therefore, we further control for the total quantity produced by other firms in Specification 2:

$$
\text { [Specification 2] } \quad q_{j, t}=\alpha_{0}+\alpha_{1} K_{j, t}+\alpha_{2} \sum_{i \neq j} K_{i, t}+\alpha_{3} \sum_{i \neq j} q_{i, t}+\varepsilon_{j, t} .
$$

Intuitively, by adding the production quantity of the other firms, the coefficient on rivals' capacity now captures the effect of excess capacity on a firm's own production. Furthermore, there is one additional reason for controlling for the production quantity of the other firms. Production technology in the cement industry might exhibit economies of scale, which implies that a larger capacity may enable firms to produce cement at lower marginal cost. Suppose a rival firm has a large production capacity. This cost advantage induces more output from this rival firm and, in response to such a cost advantage, firm $j$ must produce a smaller amount because of strategic interaction. This effect arises from economies of scale, and Specification 1 cannot capture this effect separately from the other strategic effects of capacity. Thus, we must control for production quantity of the

\footnotetext{
${ }^{17}$ Note that cost differences across the firms are already captured by the differences in function $Q_{j}^{*}(\cdot)$.
} 
Table E1: Impact of Excess Capacity on Production

\begin{tabular}{|c|c|c|c|c|c|}
\hline \multirow[b]{3}{*}{ Dependent Variable } & \multicolumn{2}{|c|}{ Specification 1} & \multicolumn{3}{|c|}{ Specification 2} \\
\hline & (i) OLS & (ii) OLS & (iii) IV & (iv) IV & (v) IV \\
\hline & $q_{j, t}$ & $q_{j, t}$ & $q_{j, t}$ & $q_{j, t}$ & $q_{j, t}$ \\
\hline Own Firm Capacity & $.950^{* * *}$ & $.948^{* * *}$ & $.955^{* * *}$ & $.955^{* * *}$ & $.954^{* * *}$ \\
\hline $\log \left(K_{j}\right)$ & (.108) & $(.112)$ & $(.110)$ & (.109) & $(.110)$ \\
\hline Other Firm Capacity & $-.493^{* * *}$ & $-.502^{* * *}$ & -.299 & -.266 & -.272 \\
\hline$\left(\log \left(\sum_{l \neq i} K_{l}\right)\right)$ & $(.200)$ & $(.226)$ & (.373) & $(.432)$ & (.423) \\
\hline Other Firm Quantity & & & -.272 & -.746 & -1.782 \\
\hline $\log \left(\sum_{l \neq i} q_{l}\right)$ & & & $(.401)$ & $(3.470)$ & $(1.655)$ \\
\hline Other Firm Quantity $^{2}$ & & & & .014 & -.147 \\
\hline$\left(\log \left(\sum_{l \neq i} q_{l}\right)\right)^{2}$ & & & & $(.103)$ & $(.216)$ \\
\hline Other Firm Quantity $^{3}$ & & & & & -.003 \\
\hline$\left(\log \left(\sum_{l \neq i} q_{l}\right)\right)^{3}$ & & & & & $(.007)$ \\
\hline Other Controls & & $\sqrt{ }$ & $\sqrt{ }$ & $\sqrt{ }$ & $\sqrt{ }$ \\
\hline Fixed Effects & & & & & \\
\hline Year & $\sqrt{ }$ & $\sqrt{ }$ & $\sqrt{ }$ & $\sqrt{ }$ & $\sqrt{ }$ \\
\hline Area & $\sqrt{ }$ & $\sqrt{ }$ & $\sqrt{ }$ & $\sqrt{ }$ & $\sqrt{ }$ \\
\hline Firm & $\sqrt{ }$ & $\sqrt{ }$ & $\sqrt{ }$ & $\sqrt{ }$ & $\sqrt{ }$ \\
\hline No. of Observations & 461 & 461 & 419 & 419 & 419 \\
\hline Adjusted $R^{2}$ & .927 & .927 & .930 & .929 & .930 \\
\hline
\end{tabular}

Note: Significance levels are denoted by $<0.10\left({ }^{*}\right),<0.05\left({ }^{* *}\right)$, and $<0.01\left(^{* * *}\right)$. The numbers in parentheses show the standard errors, clustered at the firm level. In Specification 2, instrumental variables are used to cope with endogeneity for $\sum_{i \neq j} q_{i, t}$ arising from simultaneity.

other firms. If this is the only strategic role of capacity, we would expect that $\alpha_{2}$ is zero. However, if capacity has some other strategic roles, such as a threat of future punishment as found by Devidson and Deneckere (1990), we would expect $\alpha_{2}$ to be negative.

Unfortunately, from an econometrics point of view, this relationship cannot be estimated straightforwardly, as there is an endogeneity concern between $q_{j, t}$ and $\sum_{i \neq j} q_{i, t}$ because of simultaneity, and a possible nonlinearity concern with $\sum_{i \neq j} q_{i, t}$. Thus, we use an instrumental variable approach and flexibly control for $\sum_{i \neq j} q_{i, t}$. The instruments exploited here are similar to that of Berry, Levinsohn and Pakes (1995), i.e., other firms' quantity produced in another area and other firms' number of kilns in another area. Usage of this set of instruments assumes that a firm having a cost advantage in one region must have the same cost advantage in other regions. Hopefully, these instruments solve the endogeneity problem, but to further ease concerns about endogeneity, we control for fixed effects for year, area, and firm. 
Results Table E1 summarizes the results for all specifications. The first two columns, labeled (i) OLS and (ii) OLS, present the results for Specification 1. Although both (i) and (ii) include year, area, and firm fixed effects, (ii) additionally includes regional-level GDP, and plaster and oil prices to control for demand and supply conditions. The third to fifth columns, labeled (iii) IV, (iv) IV, and (v) IV, present the results for Specification 2. As explained above, these three models under Specification 2 use an IV approach to cope with endogeneity arising from simultaneity of $q_{j, t}$ and $q_{-j, t}$. The differences among (iii), (iv), and (v) are the number of higher order terms that are included: (iii) includes up to a second order term of other firms' quantities, but (iv) and (v) include up to third and fourth order terms, respectively. Moreover, these three models include, again, regionallevel GDP, and plaster and oil prices to control for demand and supply conditions.

In both specifications, we are ultimately interested in the coefficient on other firms' capacity. When not controlling for other firms' production as in Specification 1, other firms' capacity has negative impacts on a firm's own production quantity. Regardless of the inclusion of some additional controls, this finding is robust. However, after controlling for the quantity produced by other firms as in Specification 2, other firms' capacity no longer has any impact. The absence of any effect of other firms' capacity suggests that it plays a strategic role via other firms' production behavior. When a firm competes against rival firms that have large capacity, then naturally these rival firms produce more, which results in less production by this firm. However, we do not observe other strategic aspects of excess capacity, such as the channel pointed out by Devidson and Deneckere (1990). 